\title{
Ceramic synthesis from condensed phases
}

\author{
Isabel Gonzalo-Juan ${ }^{1} \cdot$ Ralf Riedel $^{1}$
}

Received: 1 March 2016/Accepted: 18 March 2016/Published online: 13 April 2016

(C) Springer International Publishing Switzerland 2016

\begin{abstract}
Advanced ceramics have progressed significantly in the last few years. This progress is closely related to the development of new synthetic routes providing not only the preparation of known materials with improved properties, but also the discovery of novel compounds. This chapter gives an overview of established synthetic methods to prepare oxide- and non-oxide-based ceramics from precursors in condensed phases. Typical synthetic strategies performed either in liquid or solid phases are summarized. In addition, innovative synthesis methods such as sol-gel and polymer-derived pyrolysis technique to develop advanced ceramics with exceptional properties are considered.
\end{abstract}

Keywords Ceramic $\cdot$ Synthesis $\cdot$ Condensed phases

\section{Introduction}

Advanced ceramics have been technically used worldwide over the past century and stimulated current research activities in many emerging research areas ranging from fundamental science to applications in sustainable technology, energy conversion, and environmental issues.

Improving and designing or tailoring the properties of advanced ceramic materials for a wide range of applications, e.g., from engineering, resource processing and power generation to aerospace, medicine and defense-oriented applications, are the challenging tasks of modern material science. The modern industry urgently needs the

Isabel Gonzalo-Juan

gonzalo@materials.tu-darmstadt.de

1 Technische Universitaet Darmstadt, Darmstadt, Germany development and implementation of new ceramic-based materials with enhanced quality and reliability to be used in the next-generation technologies and devices. For example, there are demands for advanced ceramic material applications such as wear-, corrosion- and thermal shockresistant parts for oil, gas, mining, mineral and chemical industries, power generation, engine components, filter and catalyst supports and some other parts for automotive manufacturing, biomedical implants, armor parts and structures, filter and catalytic systems for chemical and environmental uses and many others.

In general, the properties and performance of materials strongly depend on the applied synthesis, phase composition and microstructure. Traditionally, a high-temperature ceramic synthesis, also denoted as ceramic method or shake and bake, is used to prepare inorganic solids. In this approach, solid precursors are intimately grounded in stoichiometric quantities and heated at extreme temperatures $\left(>1000{ }^{\circ} \mathrm{C}\right.$ ) for a period ranging from hours to days to facilitate interdiffusion of the solid reagents. This method has been widely used to synthesize ceramic materials like ferroelectric $\mathrm{BaTiO}_{3}$ or materials with a higher degree of complexity like cuprate-type superconductors, in which oxides contain up to six different components, such as $\mathrm{Tl}_{1-y} \mathrm{Pby}_{\mathrm{Y} 1-x} \mathrm{CaxSr}_{2} \mathrm{Cu}_{2} \mathrm{O}_{7}$ [2]. In spite of some benefits, the ceramic method faces the following drawbacks: (1) long synthesis protocol (lasting from hours up to days), (2) difficulties in controlling particle size and shape of the product and (3) only thermodynamically stable phase crystallized by this method. Therefore, in an attempt to overcome these shortcomings new synthesis routes have been intensively investigated in the past years.

In the following sections, a detailed overview of established and innovative synthetic methods to prepare oxide and non-oxide ceramics will be provided (Fig. 1). As it 

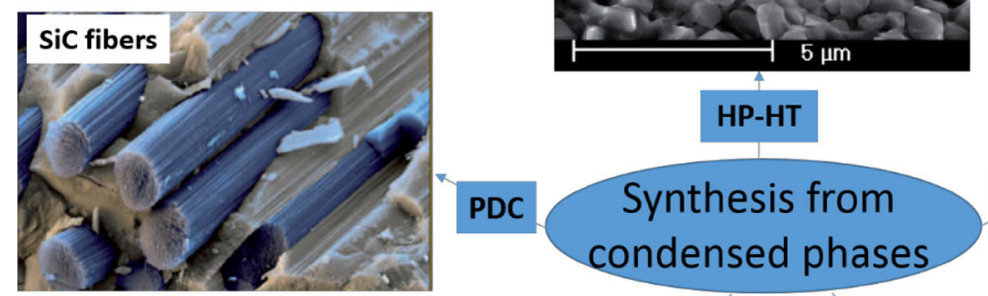

MSS
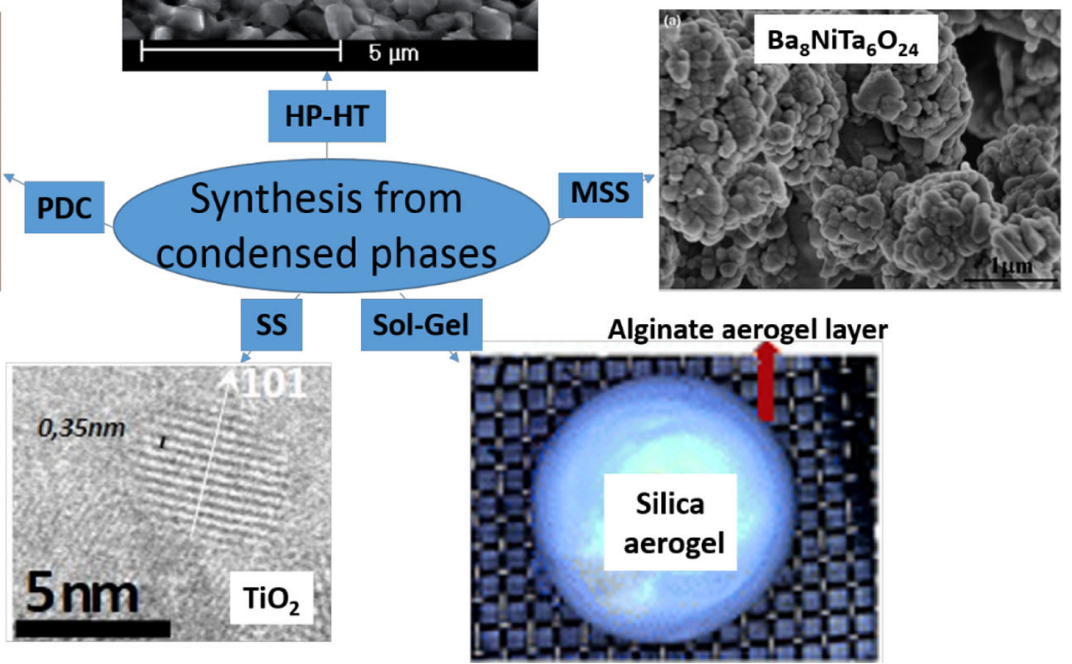

Fig. 1 Overview of the ceramic synthetic methods from condensed phases. $\left(\gamma-\mathrm{Si}_{3} \mathrm{~N}_{4}\right.$ powders - (reprinted with permission of Ref. [46]Copyright (c) 2010 WILEY-VCH Verlag GmbH \& Co. KGaA, Weinheim); $\mathrm{Ba}_{8} \mathrm{NiTa}_{6} \mathrm{O}_{24}$ powders-reprinted with permission from

would be far beyond the scope of this chapter to describe all the synthetic approaches, we will focus only on those that use precursors in condensed phase, i.e., synthetic strategies performed either in liquid or solid phases.

\section{Synthesis from the solid phase}

\section{High-pressure/high-temperature (HP-HT) synthesis}

High-pressure and high-temperature (HP-HT) materials synthesis has been developed in recent years to form new compounds/phases under solid-state conditions that are not achievable under ambient pressure. Under extreme HP-HT conditions, novel polymorphs of well-known compounds as well as completely new compounds with high coordination numbers and high oxidation states for elements with multiple valances (e.g., $\mathrm{Fe}, \mathrm{Zr}$ or $\mathrm{Ce}$ ) can be achieved.

The history of high-pressure research is first of all associated with P.W. Bridgman, a 1946 Nobel Prize Laureate "for the invention of an apparatus to produce extremely high pressures, and for the discoveries he made therewith in the field of high pressure physics". Bridgman's efforts were built upon by workers in the earth and mineral sciences, and by researches seeking to reproduce the synthesis of diamond in the laboratory. The original Bridgman anvils [3] are rarely used today; however, the
Ref. [47]—CC 2015 The American Ceramic Society; silica aerogelreprinted with permission from Ref. [48]—Copyright (C) 2014, Royal Society of Chemistry; and SiC fibers-reprinted with permission from Ref. [49])

principle of gasketed opposite anvils is implemented to various extents, in the design of most modern HP devices (Fig. 2). In this method, a thin disc of sample material surrounded by a gasket ring is compressed between two opposite anvils made from hard and strong materials. The maximum pressure achievable by this method is determined by the ratio between the force applied to the anvils and the anvil-face (culet) area, and is limited by the compressive yield strength of the anvil material. For example, the use of a laterally supported tungsten carbide anvil will allow maximum pressures of about $10 \mathrm{GPa}$ [4].

In recent years, rapid advances in instrumentation and techniques have led to a substantial growth in the range of experiments available to high-pressure researches. The workhorse tools currently available for experimental HPHT science and technology are diamond anvil-cells (DACs) and "large volume" synthesis presses including the "belt", multi anvil, toroidal and piston-cylinder designs [5] (Fig. 3). In addition to their different designs and production/operational costs, these techniques also differ in terms of their maximum achievable pressures, temperatures and sample volumes (Fig. 4).

The aforementioned apparatuses can be joined by large-scale shock-wave facilities for studies of properties and synthesis under dynamic compression, and by a group of advanced theory and simulation techniques. As promising new materials are identified and shown to be recoverable to ambient pressure with their useful 
Fig. 2 Photo of a symmetric diamond anvil cell (DAC) and the heart of the cell (inset). The DAC is a high-pressure apparatus in which a sample is compressed to high pressures by two opposing diamond anvils allowing the sample, which is contained by a metallic gasket, to be sealed between the two diamonds (reprinted with permission of S. Merkel, Univ. Lille 1)

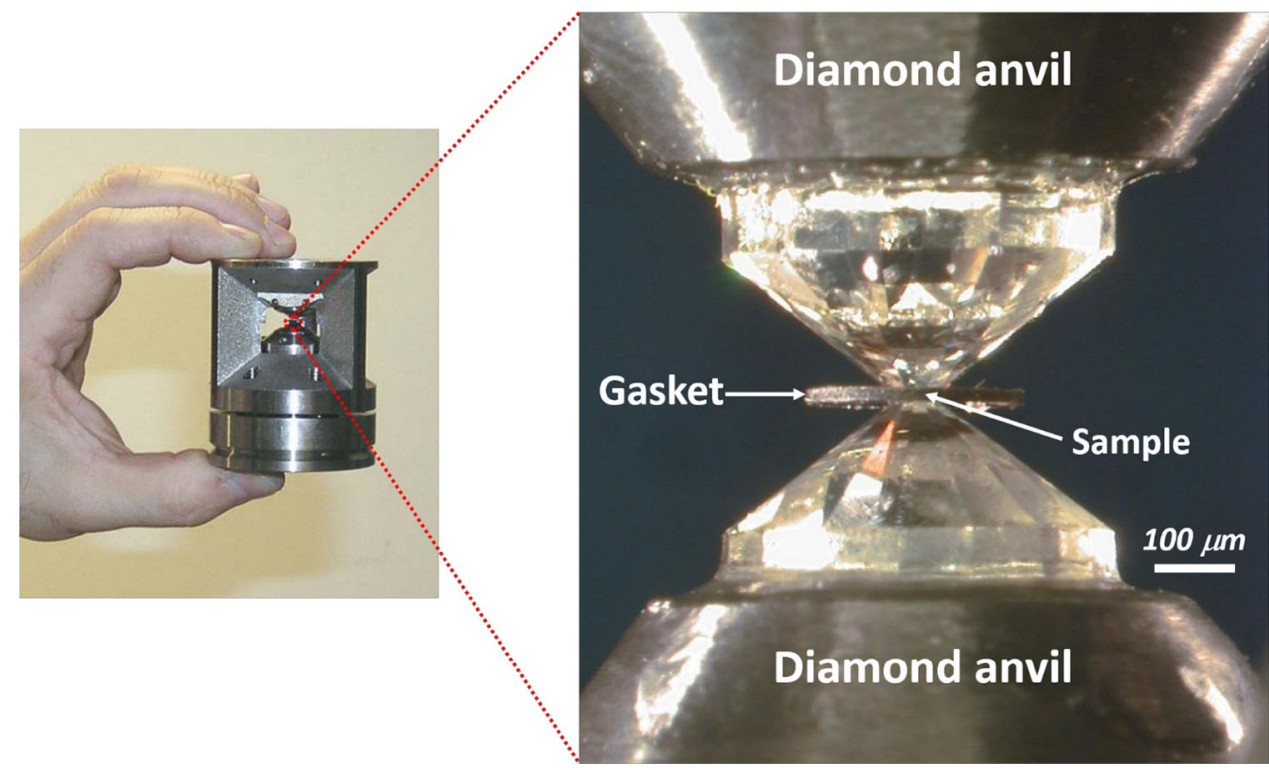

In contrast, dynamic shock waves generated by compressed gas, explosives or lasers provide the most extreme HP-HT conditions [7]. Pressures into the multi-megabar range (several hundred of $\mathrm{MPa}$ ) and extending up to 50 $\mathrm{TPa}$ with simultaneous heating to thousands or tens of thousands of ${ }^{\circ} \mathrm{C}$ can be achieved. Resistive- and laserheating techniques enable controlled heating of samples from a few hundred up to several thousand degrees, while they are held at high pressure. Despite its small sample volume, laser-heated $(\mathrm{LH}) \mathrm{DAC}$ remains the essential tool
Fig. 3 Schematics of a the piston-cylinder, b Bridgman's opposite cells, c belt and d toroid-type apparatus. The arrows indicate the directions of the applied load, reprinted with permission of Ref. [50]Copyright (C) 2012 Wiley-VCH Verlag $\mathrm{GmbH} \& \mathrm{Co}$. KGaA
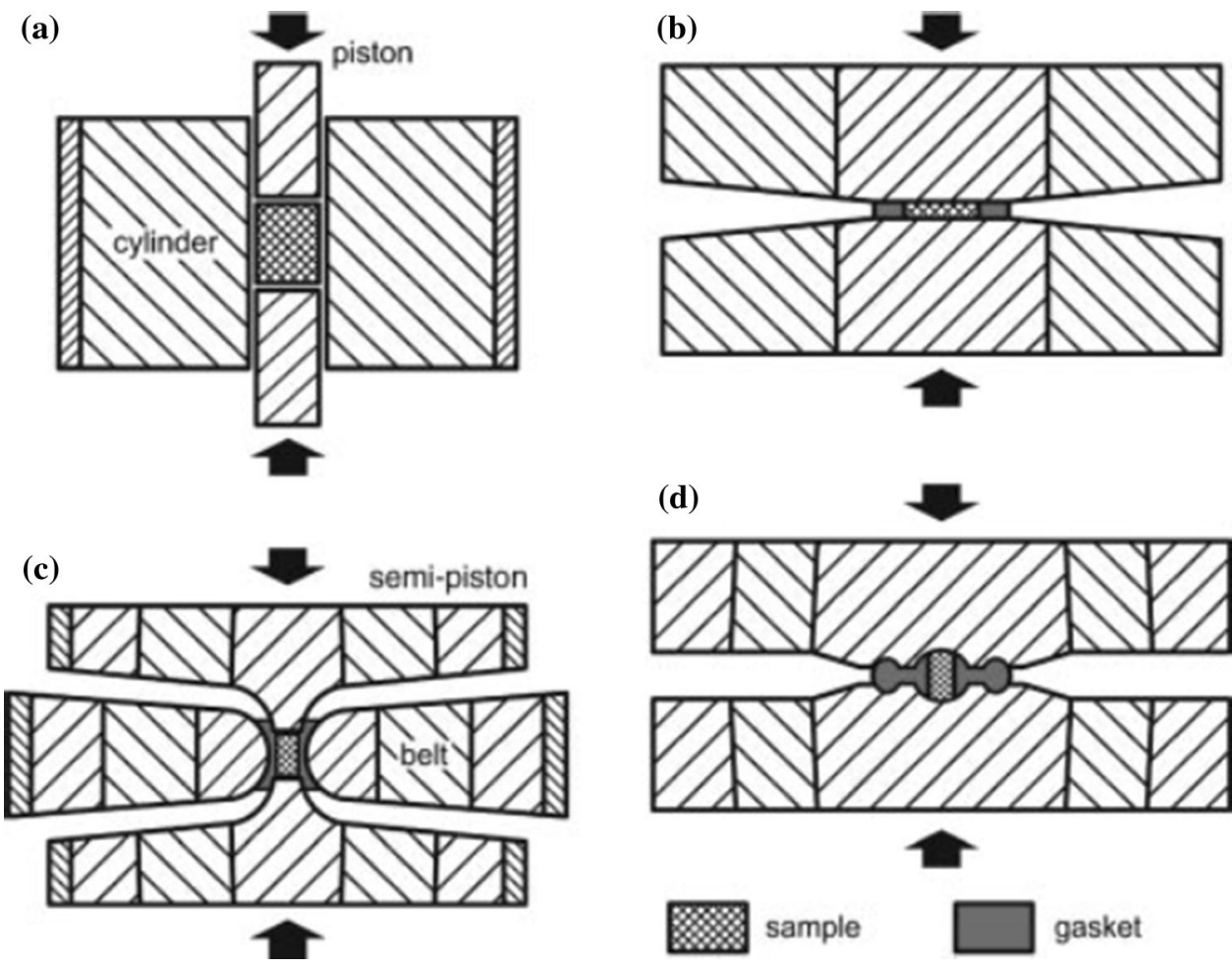

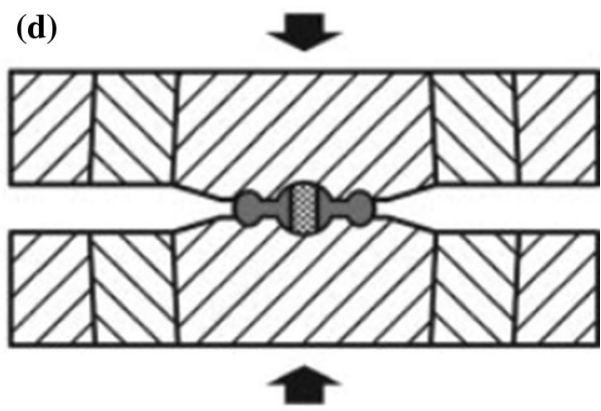

$8 \%$ sample $\quad \square$ gasket 


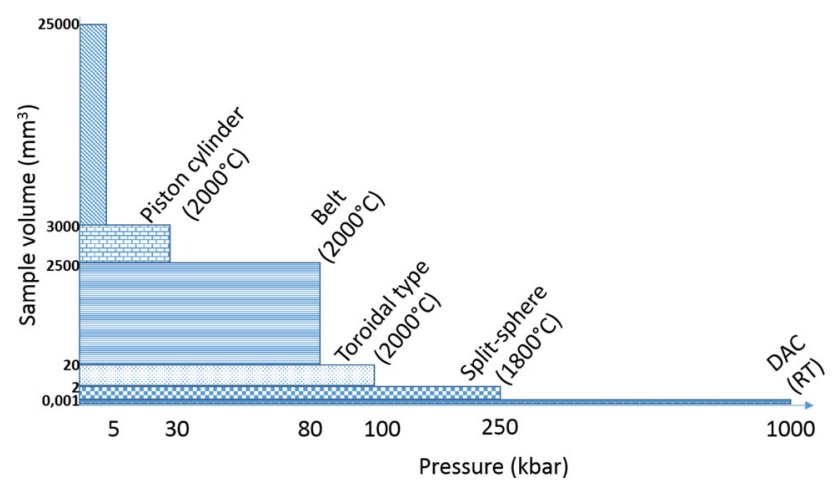

Fig. 4 Overview of the HP-HT methods showing the maximum achievable pressures, temperatures and sample volumes

for the synthesis and exploration of new high-pressure materials. There are two types of continuous-wave IR lasers for sample heating: i) solid state Nd:YAG lasers used for heating semiconductors, metals and insulators containing transition metals and ii) $\mathrm{CO}_{2}$ lasers used in experiments with non-conducting inorganic (oxides, silicates, nitrides, etc.) and organic materials.

The use of high pressures combined with high temperatures and compositional variables provides an opportunity to synthesize entirely new classes of materials and/or to tune their electronic, magnetic and structural properties for a wide range of applications. However, due to high operational costs and comparably low material yield, industrial HP-HT synthesis is generally limited to the production of diamond and c-BN. Nevertheless, during the past few decades numerous novel HP materials have been discovered and investigated. Some of these HP-phases may be of potential interest for industrial applications due to their high elastic moduli and hardness. Among these, cubic spinel-type silicon nitride $\left(\gamma-\mathrm{Si}_{3} \mathrm{~N}_{4}\right)$ is the most promising material on the way to mass production. It was synthesized for the first time from amorphous and crystalline (alpha and beta) $\mathrm{Si}_{3} \mathrm{~N}_{4}$ at high pressures (15-30 GPa) and high temperatures (2200-2800 K) using LH-DAC [8] (Fig. 5). Recently, a novel crystalline boron oxynitride (BON) phase has been synthesized under static pressures exceeding 15 GPa and temperatures above $1900{ }^{\circ} \mathrm{C}$, from molar mixtures of $\mathrm{B}_{2} \mathrm{O}_{3}$ and hexagonal $\mathrm{BN}$ [9]. Additionally, HP materials may combine high elastic moduli and hardness with interesting thermal, optoelectronic and semiconducting, magnetic or superconducting properties. For example, the high-pressure zirconium and hafnium nitrides with the stoichiometry $\mathrm{M}_{3} \mathrm{~N}_{4}(\mathrm{M}=\mathrm{Zr}$, Hf) were synthesized for the first time in an LH-DAC at pressures up to $18 \mathrm{GPa}$ and temperatures up to $3000 \mathrm{~K}$ [10]. These materials have a cubic crystalline structure $\left(\mathrm{c}-\mathrm{M}_{3} \mathrm{~N}_{4}\right)$ with a $\mathrm{Th}_{3} \mathrm{P}_{4}$-structure, where $\mathrm{M}$-cations are eightfold coordinated by $\mathrm{N}$ anions.
The $\mathrm{c}-\mathrm{M}_{3} \mathrm{~N}_{4}$ phases, which were the first binary nitrides with such a high coordination number, exhibit a high bulk moduli (around $250 \mathrm{GPa}$ ) and accordingly high hardness.

\section{Molten salt (MS) synthesis}

Molten salt (MS) synthesis has been proved to be one of the simplest, most versatile and cost-effective approaches to obtain crystalline, chemically purified, single-phase powders. Traditionally, molten inorganic salts are used as high-temperature solvents, mimicking the crystal nucleation and growth conditions in conventional solvents. In molten salt synthesis, a large amount of salt with a low melting point is heated above its melting temperature acting as the solvent (reaction medium). This feature provides significant advantages as compared to solid state reaction or mild synthetic approaches using conventional solvents. For example, the synthesis of strong covalently bonded solids, such as borides, carbide and nitrides, using mild synthetic conditions yields poorly crystalline or even amorphous materials. To overcome the energy barrier of crystal nucleation, a much higher temperature is usually required, which, however, exceeds the operation window for most of the organic solvents under ambient pressure. This situation stimulated the synthesis in inorganic MS media which offer the following advantages as compared to synthetic routes in conventional solvents: (1) an operational temperature window from $100{ }^{\circ} \mathrm{C}$ to over $1000{ }^{\circ} \mathrm{C}$ without developing dangerous pressures, (2) high oxidizing potential, (3) high mass transfer, (4) high thermal conductivity and (5) low viscosities and densities (Table 1).

The requirements on the salt are that they are stable, readily available, inexpensive and easily washed away with water. A low melting temperature is desirable, and a eutectic composition (the composition at the minimum liquidus temperature) is often used. Typical salts used in MS synthesis are halides, hydroxides and oxosalts (Table 2). In many cases, eutectic mixtures of salts are used to reduce the liquid formation temperature. For example, the melting points of $\mathrm{NaCl}$ and $\mathrm{KCl}$ are 801 and $770{ }^{\circ} \mathrm{C}$, respectively. However, the eutectic composition of a mixture of $0.5 \mathrm{NaCl}-0.5 \mathrm{KCl}$ exhibits a melting point of $650{ }^{\circ} \mathrm{C}$. A mixture of $0.635 \mathrm{Li}_{2} \mathrm{SO}_{4}-0.365 \mathrm{Na}_{2} \mathrm{SO}_{4}$ is the most commonly used molten salt among sulfates because of its low melting temperature, which is $594{ }^{\circ} \mathrm{C}$, whereas that of $\mathrm{Na}_{2} \mathrm{SO}_{4}-\mathrm{K}_{2} \mathrm{SO}_{4}$ is $823{ }^{\circ} \mathrm{C}$. Other requirements are (1) a low vapor pressure of the molten salt at the melting temperature and (2) no undesirable reactions of the molten salt with either the reactants or the product.

During the reaction, the molten salts provide the following advantages: (1) increase the reaction rate and reduce the reaction temperature by increasing the contact 

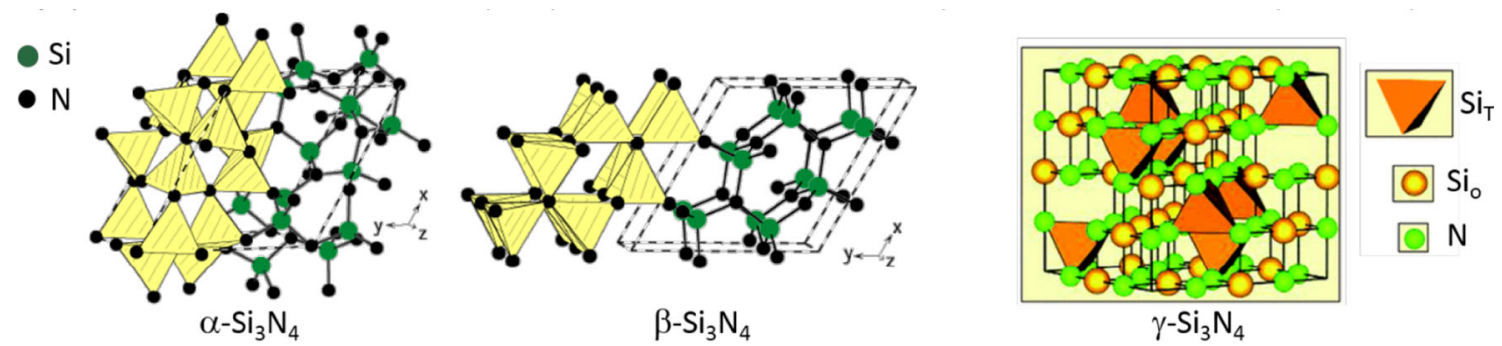

$$
\begin{aligned}
& \gamma \mathrm{Si}_{3} \mathrm{~N}_{4} \text { has the following properties: } \\
& \text { i) very high elastic moduli, } \\
& \text { ii) it is the third hardest material next to diamond and cubic } \\
& \text { boron nitride (c-BN), } \\
& \text { iii) high thermal stability even in air (until } 1673 \mathrm{~K} \text { ) and, } \\
& \text { iv) it has a 3,3 eV band gap. }
\end{aligned}
$$

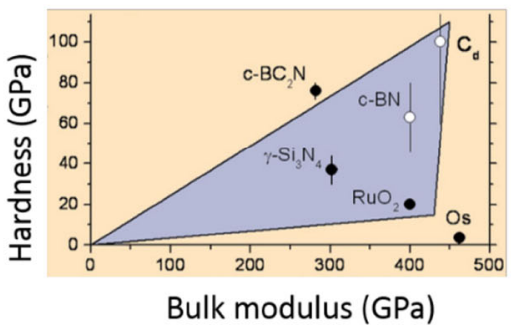

Fig. 5 CUBIC SILICON NITRIDE $\left(\gamma-\mathrm{Si}_{3} \mathrm{~N}_{4}\right)$ (reprinted with permission of Ref. [46]-Copyright $\odot 2010$ WILEY-VCH Verlag GmbH \& Co. KGaA, Weinheim)

Table 1 Physicochemical properties of a molten $\mathrm{NaCl}$ at $850{ }^{\circ} \mathrm{C}$ and a solution of $\mathrm{NaCl} 10^{-1} \mathrm{M}$ at $25{ }^{\circ} \mathrm{C}$

\begin{tabular}{lllll}
\hline Electrolyte & Ion concentration $\left(\mathrm{mol} \mathrm{L}^{-1}\right)$ & Density $\left(\mathrm{g} \mathrm{cm}^{-3}\right)$ & Electrical conductivity $\left(\mathrm{S} \mathrm{cm}{ }^{-1}\right)$ & $\mathrm{Viscosity}(\mathrm{cP})^{\circ}$ \\
\hline Molten $\mathrm{NaCl}$ at $850{ }^{\circ} \mathrm{C}$ & 26 & 1.53 & 3.6 & 1.2 \\
$\mathrm{NaCl} 10^{-1} \mathrm{~mol} \mathrm{~L}^{-1}$ at $25{ }^{\circ} \mathrm{C}$ & $10^{-1}$ & 1.00 & $1.07 \times 10^{-1}$ & 1.01 \\
\hline
\end{tabular}

Table 2 Melting points and compositions of some commonly used metal halides, hydroxides and oxosalt systems

\begin{tabular}{llll}
\hline Salt system & & Composition $(\mathrm{mol} \%)$ & Melting point $\left({ }^{\circ} \mathrm{C}\right)$ \\
\hline Halides & $\mathrm{LiCl} / \mathrm{KCl}$ & $59 / 41^{\mathrm{a}}$ & 352 \\
& $\mathrm{NaCl} / \mathrm{KCl}$ & $50 / 50$ & 658 \\
& $\mathrm{AlCl} / \mathrm{NaCl}$ & $50 / 50$ & 154 \\
& $\mathrm{KCl} / \mathrm{ZnCl} 2$ & $48 / 52$ & 228 \\
& $\mathrm{LiF} / \mathrm{NaF} / \mathrm{KF}$ & $46.5 / 11.5 / 42^{\mathrm{a}}$ & 459 \\
& $\mathrm{LI} / \mathrm{KI}$ & $63 / 37^{\mathrm{a}}$ & 286 \\
Hydroxides & $\mathrm{NaOH} / \mathrm{KOH}$ & $51 / 49^{\mathrm{a}}$ & 170 \\
Oxosalts & $\mathrm{LiNO}_{3} / \mathrm{KNO}_{3}$ & $43 / 57^{\mathrm{a}}$ & 132 \\
& $\mathrm{Li}_{2} \mathrm{SO}_{4} / \mathrm{K}_{2} \mathrm{SO}_{4}$ & $71.6 / 28.4^{\mathrm{a}}$ & 535 \\
& $\mathrm{Li}_{2} \mathrm{CO}_{3} / \mathrm{K}_{2} \mathrm{CO}_{3}$ & $50 / 50$ & 503 \\
\hline
\end{tabular}

area of the reactant particles (precursors) and the mobility of the reactant species in the liquid molten salt; (2) increase the degree of homogeneity (the distribution of the constituting elements in the solid solution); (3) allow the control of the particle size and shape by controlling the rate of the Ostwald ripening mechanism (temperature and heating time); and (4) prevent the direct contact between the particles by covering their surfaces allowing the control of the aggregation state.

The solubility of oxides in molten salts varies greatly from less than $1 \times 10^{-10} \mathrm{~mol}$ fraction to more than $0.5 \mathrm{~mol}$ fraction, typically $1 \times 10^{-3}-1 \times 10^{-7}$ mol fraction. In many cases, the formation reaction occurs in the presence of solid reactant particles. In this sense, molten salt is somewhat different from ordinary solvents, which dissolve all reactant particles and the product precipitates from a homogeneous liquid phase.

Generally, a complex oxide powder is prepared from precursors following the procedure shown in the scheme of Fig. 6. A mixture of solid precursor particles and salt is heated above the melting point of the salt. At the melting temperature of the molten salt, the product particles are formed. The characteristics of the product powder are controlled by selecting the temperature and duration of the heating (typical conditions are temperatures between 800 and $1000{ }^{\circ} \mathrm{C}$ during $30-60 \mathrm{~min}$ ). Finally, the reacted mass 


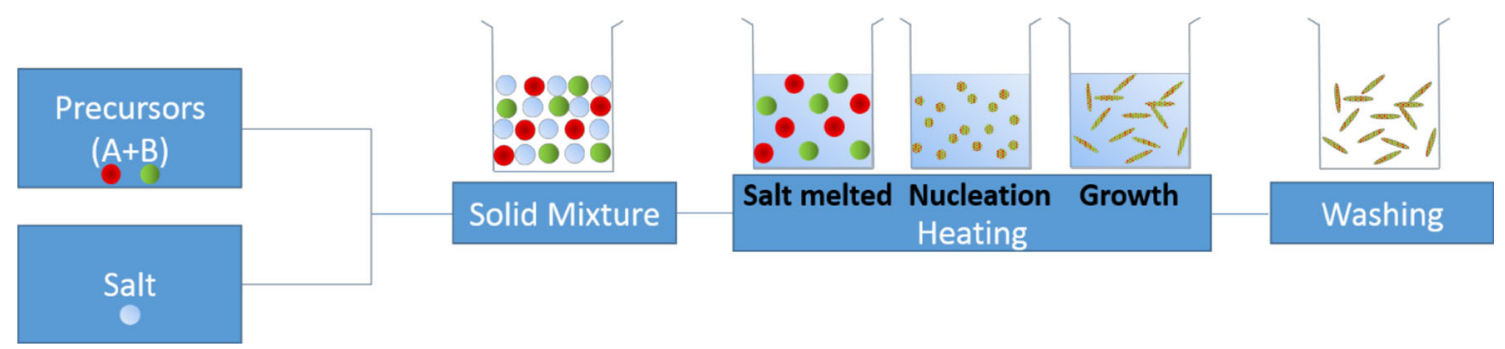

Fig. 6 Scheme of the general molten salt synthesis procedure
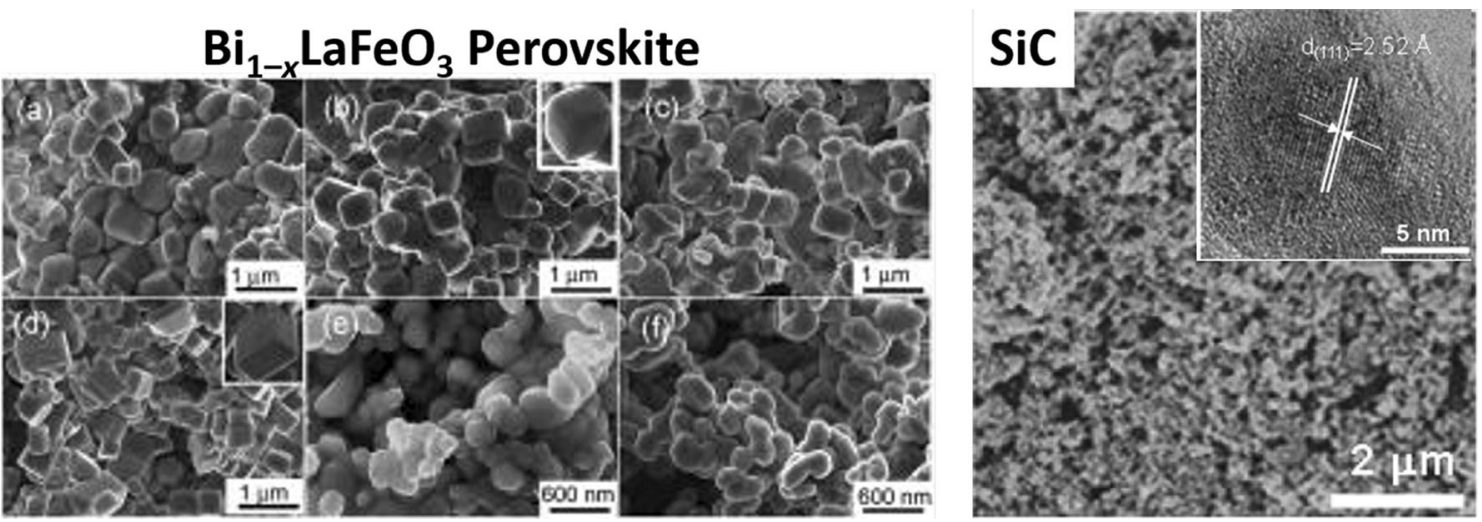

Fig. 7 Structure and shape evolution of $\mathrm{Bi}_{1-x} \mathrm{LaFeO}_{3}$ perovskite microcrystals synthesized by molten salt in different conditions (right side, reprinted with permission from Ref. [51]—Copyright (C) 2008 WILEY-VCH Verlag GmbH \& Co. KGaA, Weinheim).

is cooled to room temperature and washed with an appropriate solvent (typically, water) to remove the salt. The complex oxide powder is obtained after drying.

Molten salt synthesis has been an important tool for researchers to discover and explore crystals with different shapes and compositionally complex metal oxides such as perovskites (Fig. 7, right). In recent years, many ceramic compounds have been synthesized through the molten salt method, such as $\mathrm{ZnWO}_{4}: \mathrm{Eu}^{3+}$ nanophosphors and $\mathrm{Gd}_{2-}$ $\mathrm{MO}_{6}: \mathrm{Eu}^{3+}(\mathrm{M}=\mathrm{W}, \mathrm{Mo})$ phosphors [11, 12]. Moreover, the MS process has indeed already succeeded in the synthesis of highly crystalline nanocrystals based on strongly covalently bonded materials such as metal carbides and borides (Fig. 7, left).

\section{Polymer-to-ceramic transformation synthesis}

Polymer-derived ceramics (PDCs) describe a new class of advanced ceramics, particularly in the ternary and multinary systems $\mathrm{SiCO}, \mathrm{SiCN}, \mathrm{Si}(\mathrm{M}) \mathrm{CO}$ and $\mathrm{Si}(\mathrm{M}) \mathrm{CN}$ $(\mathrm{M}=$ metal), synthesized by the thermal treatment of appropriate preceramic polymers in an inert or reactive atmosphere in the temperature range between 800 and $1500{ }^{\circ} \mathrm{C}$ (Fig. 8). They exhibit two main advantages: (1)
Morphological control for $\mathrm{SiC}$ nanostructures synthesized from silica nanoparticles and MS-carbon (left side reprinted with permission from Ref. [52]—Copyright (c) 2013 American Chemical Society)

the ceramics obtained from polymeric precursors usually yield a chemical composition not achievable by other techniques and (2) the possibility of combining the shaping and synthesis of ceramics, i.e., components can be shaped at the precursor stage by conventional plastic-forming techniques, such as spinning, blowing, injection molding, warm pressing and resin transfer molding, and then converted into ceramics by treatments typically above $800{ }^{\circ} \mathrm{C}$.

The overall process of the formation of PDCs consists of four steps (Fig. 9): (1) the synthesis of preceramic polymers from suitable monomers; (2) cross-linking of the polymers at low temperatures $\left(100-400{ }^{\circ} \mathrm{C}\right)$, followed by (3) a ceramization step via pyrolysis at temperatures ranging from 800 to $1500{ }^{\circ} \mathrm{C}$. While mainly amorphous ceramics are obtained upon pyrolysis, subsequent annealing at higher temperatures can lead to (poly)crystalline materials. In the following, we will describe the individual processing steps in more detail.

\section{Preceramic polymer synthesis}

The preceramic polymers represent inorganic/ organometallic systems that provide ceramics with a tailored chemical composition and a defined nanostructural 
Fig. 8 Main classes of Sipolymer as precursors for ceramics (reprinted with permission from Ref. [22]—C 2010 The American Ceramic Society)

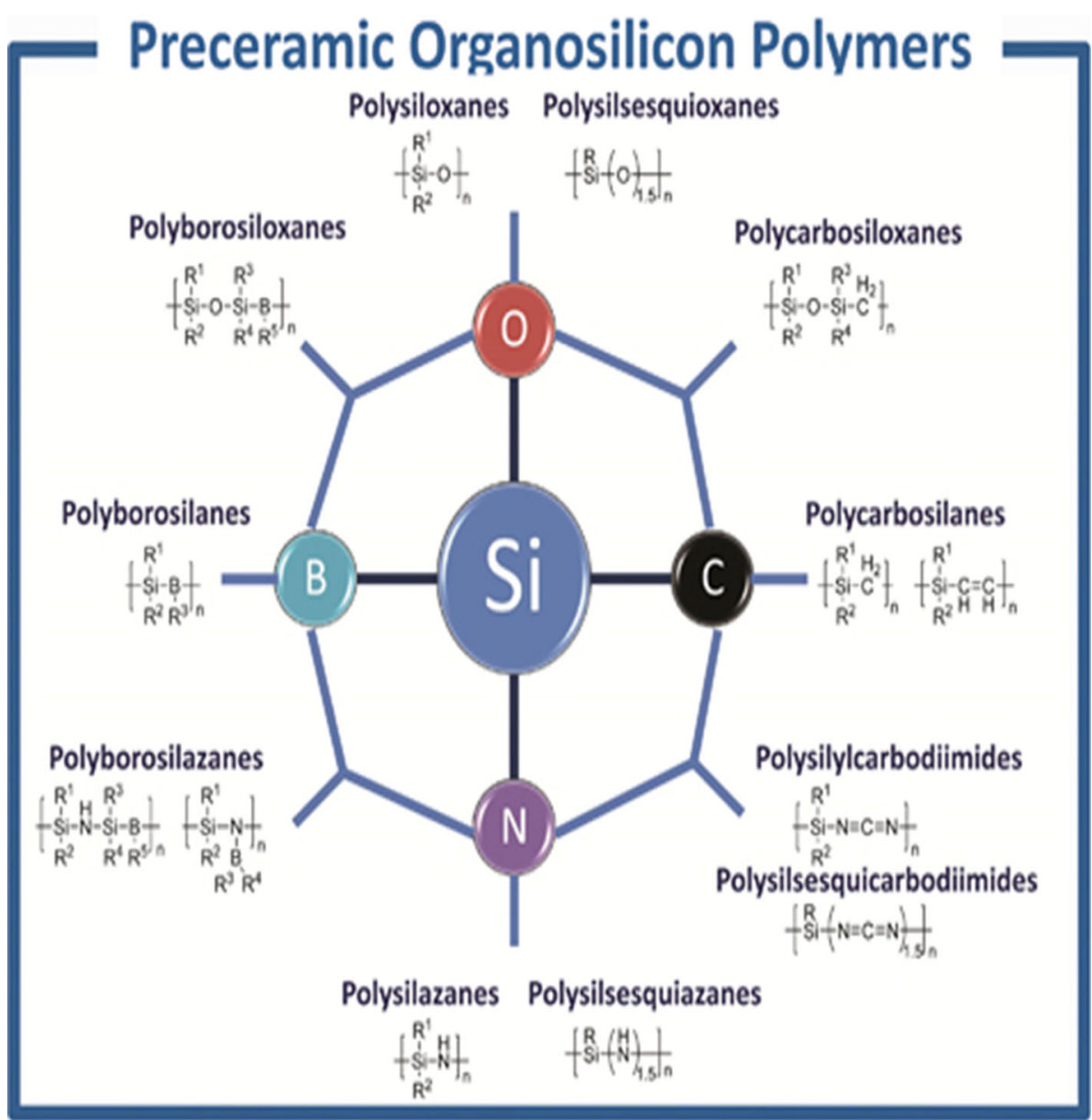

organization. Common preceramic polymers for the preparation of PDCs are polysilanes, polycarbosilanes and polysiloxanes, as well as polysilazanes and polysilylcarbodiimides (Fig. 8).

The preceramic polymers have to meet the following requirements: (1) they should possess a high molecular weight to avoid volatilization of low molecular components; (2) they should have appropriate rheological properties and solubility for the shaping process; and (3) they must have latent reactivity (presence of functional groups) for the cross-linking and curing steps. The molecular structure and type of the preceramic polymer is one of the key issues in PDCs due to influence on (1) the overall composition, (2) the number of phases and the phase distribution and (3) the microstructure of the final ceramic product. Thus, the macroscopic chemical and
Fig. 9 Polymer-to-ceramic transformation of preceramic polymers [53]

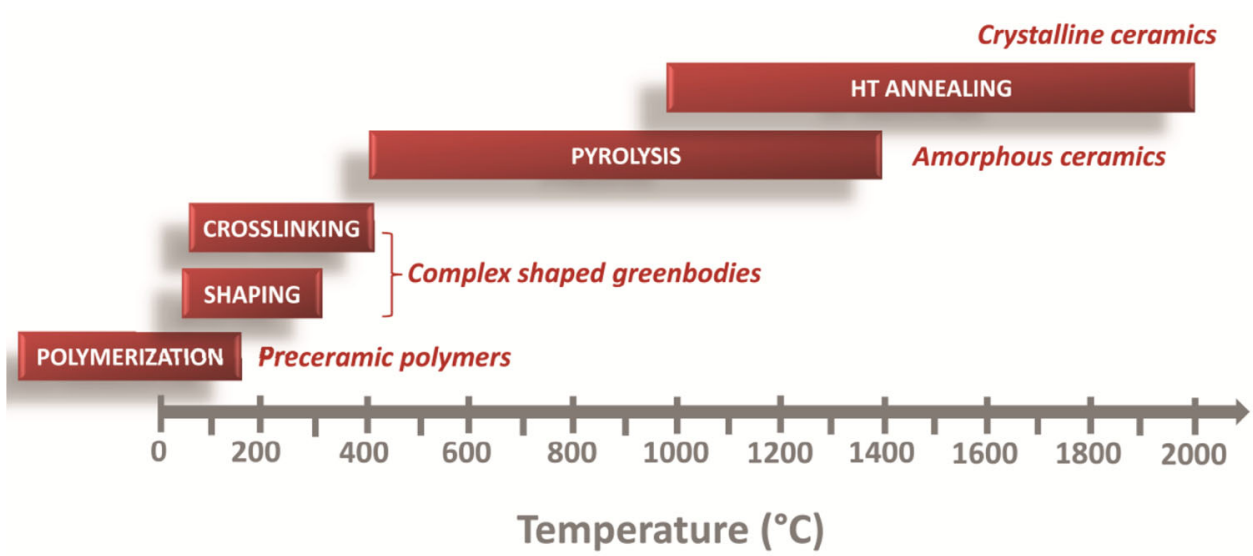




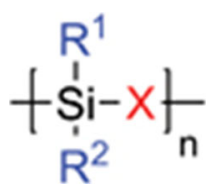

Fig. 10 General oversimplified representation of the molecular structure of preceramic organosilicon compounds (reprinted with permission from Ref. [22]_C 2010 The American Ceramic Society)

physical properties of PDCs can be tailored by the design of the molecular precursor.

An oversimplified general formula of an organosilicon polymer suitable as a precursor for the synthesis of ceramics is presented in Fig. 10. There are two important parameters to modify and design the preceramic compound at the molecular level: (1) the group (X) of the polymer backbone and (2) the substituents $\mathrm{R}^{1}$ and $\mathrm{R}^{2}$ bonded to silicon. The chlorosilanes $\mathrm{R}_{x} \mathrm{SiCl}_{(4-x)}(x=0-3 ; \mathrm{R}=$ organic side group) are the most frequently used starting compounds because of their commercial availability and their low cost. The syntheses of the most representative classes of Si-polymers from organo chlorosilanes are shown in Fig. 8. The variation of (X) results in different classes of Si-based polymers such as poly(organosilanes) with $\mathrm{X}=\mathrm{Si}$, poly(organocarbosilanes) with $\mathrm{X}=\mathrm{CH}_{2}$, poly(organosiloxanes) with $\mathrm{X}=\mathrm{O}$, poly(organosilazanes) with $\mathrm{X}=\mathrm{NH}$ and poly(organosilylcarbodiimides) with $\mathrm{X}=[\mathrm{N}=\mathrm{C}=\mathrm{N}]$ (Fig. 8) [13].

\section{Cross-linking}

During cross-linking, the precursors are converted into organic/inorganic materials with enhanced molecular weight, which reduces the loss of low-weight components of the precursor and minimizes fragmentation processes during the ceramization step. Since the cross-linked polymers are basically infusible materials they retain their shape upon pyrolysis and do not melt during ceramization. Depending on the chemistry of the precursor polymer and the reaction conditions, different chemical reactions can take place during the cross-linking process:

Polycarbosilanes can be cross-linked by either oxygen or electron beam (e-beam) curing. In the presence of oxygen, the cross-linking process occurs via radical mechanism which involves $\mathrm{Si}-\mathrm{H}$ and $\mathrm{Si}-\mathrm{CH}_{3}$ groups to form $\mathrm{Si}-\mathrm{OH}, \mathrm{Si}-\mathrm{O}-\mathrm{Si}$ and $\mathrm{C}=\mathrm{O}$ units. The ceramization of those cross-linked polymers yields silicon carbide-based materials (e.g., SiC fibers) containing high oxygen content (e.g., 10-12\%). Cross-linking of polycarbosilanes in the absence of oxygen (using e-beam) involves reactions of $\mathrm{Si}-$ $\mathrm{H}$ bonds with $\mathrm{Si}-\mathrm{CH}_{2}$ groups, leading to $\mathrm{Si}-\mathrm{CH}-\mathrm{Si}$ linkages. Silicon carbide materials cross-linked via e-beam radiation show low oxygen content $(0.2-0.3 \%)$.
Polysiloxanes can be cross-linked via condensation, transition metal-catalyzed addition and by free radical initiation mechanisms. The cross-linking of polysiloxanes containing either methyl or vinyl groups can be performed thermally, by using peroxides. Furthermore, cross-linking reactions can occur between silicon hydride units and $\mathrm{Si}-$ vinyl groups, either thermally or via metal salt catalysis. In case of polysiloxanes containing hydroxyl and alkoxy groups, condensation of $\mathrm{Si}-\mathrm{OH}$ units as well as hydrolysis of alkoxy groups leads to the formation of the $\mathrm{Si}-\mathrm{O}-\mathrm{Si}$ bonds.

Polysilazanes can be cross-linked either thermally or using chemical reagents, such as catalysts and peroxides. During the thermal cross-linking process of appropriate substituted polysilazanes, four major reactions can occur: (1) hydrosilylation in polysilazanes, which are composed of $\mathrm{Si}-\mathrm{H}$ and vinyl groups, at low temperatures (starting at $100-120^{\circ} \mathrm{C}$ ) leads to the formation of $\mathrm{Si}-\mathrm{C}$ linkages; (2) vinyl polymerization is an additional process, which occurs at temperatures higher than $300{ }^{\circ} \mathrm{C}$; (3) transamination occurs at temperatures above $200{ }^{\circ} \mathrm{C}$ and is characterized by a mass loss (i.e., evolution of amines, ammonia or oligomeric silazanes) which leads to a decrease in the nitrogen content of the ceramic materials upon pyrolysis; and finally, (4) dehydrocoupling reactions between $\mathrm{Si}-\mathrm{H}$ and $\mathrm{N}-\mathrm{H}$ units as well as between $\mathrm{Si}-\mathrm{H}$ and $\mathrm{Si}-\mathrm{H}$ units at higher temperatures (ca. $300{ }^{\circ} \mathrm{C}$ ) yield the formation of new $\mathrm{Si}-\mathrm{N}$ bonds or $\mathrm{Si}-\mathrm{Si}$ bonds, respectively.

\section{Pyrolysis}

Finally, the cross-linked precursors are treated at elevated temperatures (i.e., $600-1000{ }^{\circ} \mathrm{C}$ ). Within this temperature range, thermolysis and evolution of organic groups of the cross-linked polymers occur and, consequently, amorphous covalently bonded ceramics are attained [14]. The reactions that occur during pyrolysis may be investigated by means of ex situ solid-state nuclear magnetic resonance (NMR), Fourier transform infrared (FTIR) and Raman spectroscopy, as well as thermogravimetric analysis (TGA) coupled with in situ mass spectrometry (MS) and FTIR spectroscopy.

Polycarbosilanes can be pyrolyzed at temperatures ranging from 800 to $1000{ }^{\circ} \mathrm{C}$, where the polycarbosilanes are transformed into inorganic materials with the evolution of hydrogen and methane. The ceramics obtained upon pyrolysis at $T>800{ }^{\circ} \mathrm{C}$ can be described as hydrogenated silicon carbide with excess carbon. The amorphous ceramic begins to crystallize into silicon carbide at temperatures exceeding $1000{ }^{\circ} \mathrm{C}$ with the simultaneous evolution of hydrogen $[15,16]$.

Cross-linked polysiloxanes are converted into silicon oxycarbide (SiOC) glasses upon pyrolysis at temperatures between 600 and $1000{ }^{\circ} \mathrm{C}$ [17-19]. The ceramization occurs via the evolution of hydrocarbons and hydrogen. 
Additionally, various redistribution reactions between $\mathrm{Si}-$ $\mathrm{O}, \mathrm{Si}-\mathrm{C}$ and $\mathrm{Si}-\mathrm{H}$ bonds can occur leading to the evolution of low molecular weight silanes [20] and, consequently, decreasing the ceramic yield. The achieved materials consist of amorphous SiOC and residual free carbon phases.

The processes that occur upon pyrolysis of polysilazanes and poly(carbo)silazanes are rather complex. While the ceramization of cross-linked perhydropolysilazane (carbon-free precursor) yields binary amorphous or polycrystalline $\mathrm{Si}_{3} \mathrm{~N}$, the pyrolysis of either polyhydrido(organo)silazanes or polysilylcarbodiimides leads to the formation of amorphous SiCN with different microstructures. SiCN derived from polyhydrido(organo)silazanes is an amorphous phase and exhibits a mixed bond configuration (tetrahedrally coordinated silicon from $\mathrm{SiC}_{4}, \mathrm{SiC}_{3} \mathrm{~N}, \mathrm{SiC}_{2} \mathrm{~N}_{2}$ and $\mathrm{SiCN}_{3}$ to $\mathrm{SiN}_{4}$ ) as well as free carbon, whereas the pyrolysis of polysilylcarbodiimides ends up with an amorphous nanocomposite composed of $\mathrm{Si}_{3} \mathrm{~N}_{4}, \mathrm{SiC}$ and free carbon phase [21-27].

The addition of solid fillers to preceramic polymers provides the possibility of manufacturing crack-free ceramics with functional properties (Fig. 11). To control the filler-containing processing of PDCs, two different approaches have been reported in the literature:

Inert or passive fillers are ceramic powders that do not react (1) with the ceramic residue resulting from the preceramic polymer, (2) the decomposition gases or (3) the heating atmosphere [22]. Such fillers simply dilute the preceramic polymer, which decreases the amount of gases generated and reduces the associated volume shrinkage, and finally reduces crack formation during the polymer-toceramic transformation process. The final ceramic is constituted by a polymer-derived matrix containing inert or passive filler particles (Fig. 12).
Active fillers are metallic or intermetallic powders that react with the decomposition gases generated during pyrolysis, or with the heating atmosphere or (less frequently) with the ceramic residue obtained from the preceramic polymer [28, 29]. For handling and safety reasons, the active fillers are normally quite coarse (in the micrometer range), as small metallic particles may exhibit pyrophoricity. Typical products of the chemical reactions between the preceramic polymer and the filler particles are carbides, nitrides or silicide phases, with a significant impact on the overall shrinkage. In fact, the metal-to-ceramic transformation generally occurs with a large volume expansion, due to a large density decrease, which compensates for the shrinkage associated with the conversion of the polymers to the ceramic material. Solid particles and the in situ reaction with the filler reduce the amount of gases generated and the local gas pressure, respectively, therefore enabling the fabrication of near-net shape, bulk, uncracked ceramic components [28].

To tune functional applications of polymer-derived ceramics, direct chemical modification of preceramic polymers using metal alkoxides or other chemical precursors (liquid or gaseous) has been studied in recent years. Metal alkoxides have been added to the preceramic polymers for various purposes, e.g., to enhance the cross-linking of Si-based polymers, control crystallization processes of the resulting ceramic residue, improve the high-temperature stability of PDCs or afford functional properties such as sensoric, magnetic or catalytic features. From the microstructural point of view, these additions result in Sibased ceramic residues, containing additional amorphous or crystalline oxidic or non-oxidic phases. In some cases, the additions have allowed the preceramic polymers to retain their plastic shaping capability, while in other cases
Fig. 11 Processing and thermolysis of preceramic polymers without (right) and with (left) fillers (reprinted with permission form Ref. [22]- (C) 2010 The American Ceramic Society)
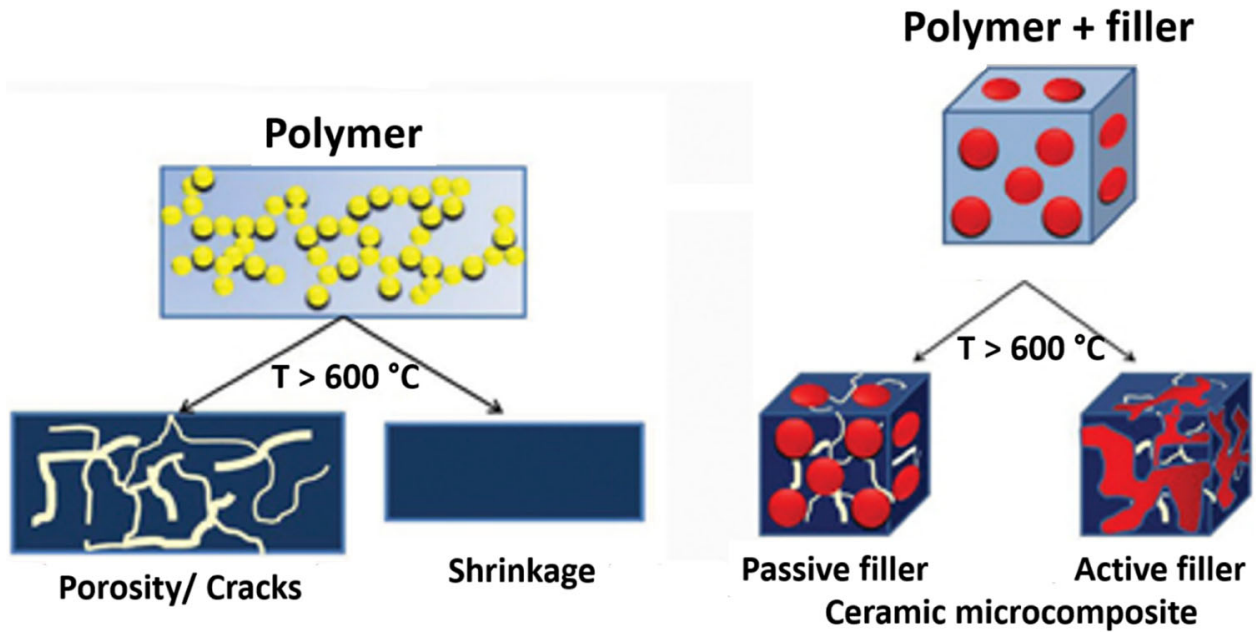


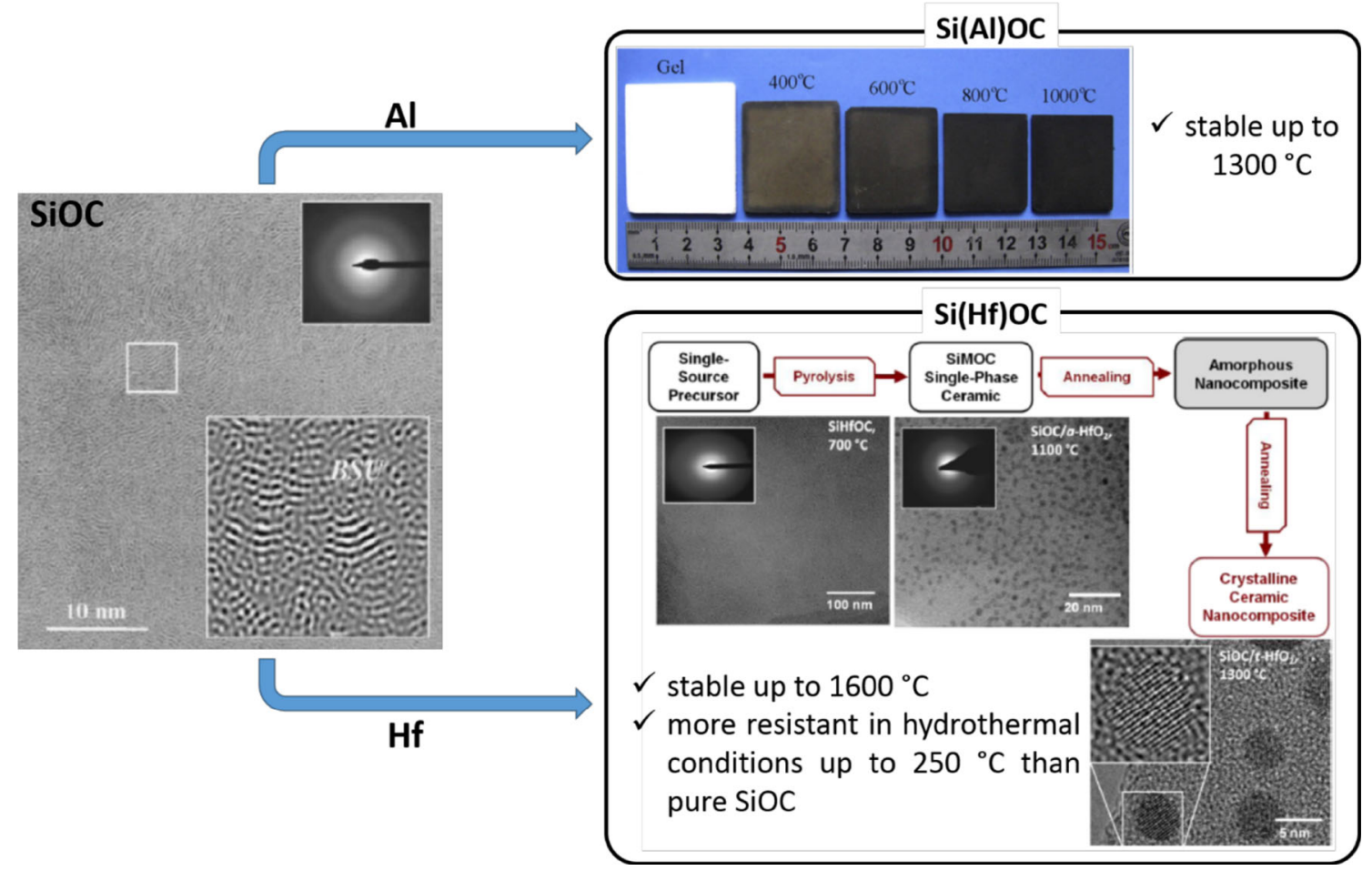

Fig. 12 Chemical modification of SiOC [22] (Copyright (C) 2010 The American Ceramic Society) with Al (top) and Hf (bottom) to extend the temperature stability of the amorphous residues SiAlOC [54] (Copyright (C) 2011 Elsevier B.V.) and SiHfOC [53], respectively

the increase of the degree of cross-linking prevents their viscous flow.

The chemical modification of the polymers by the solgel technique, with metal alkoxides, represents an excellent opportunity to extend the temperature stability of the amorphous residues. As an example, Al-containing alkoxide compounds, such as alumatrane $\left(\mathrm{C}_{6} \mathrm{H}_{12} \mathrm{NOAl}\right)$, added to commercial silicones, led to an $\mathrm{SiAlOC}$ residue, stable up to $1300{ }^{\circ} \mathrm{C}$ [30]. The potential of the additives, however, does not simply rely on avoiding phase separation, but also on allowing controlled crystallization with the development of new phases. Zr- and Hf-containing materials also represent an interesting example for the excellent high-temperature stability of the related nanocomposites [31-33]; zirconia and hafnia, being particularly resistant against carbothermal reduction, may form silicates, such as zircon $\left(\mathrm{ZrSiO}_{4}\right)$ and hafnon $\left(\mathrm{HfSiO}_{4}\right)$, stable up to $1600{ }^{\circ} \mathrm{C}$. Moreover, SiZrOC and SiHfOC are more resistant under hydrothermal conditions up to $250{ }^{\circ} \mathrm{C}$ than pure $\mathrm{SiOC}$ facilitating a synergic effect, i.e., while zirconia and hafnia have a relatively low, but appreciable, solubility in water under the testing conditions, the SiCO matrix protects the dispersed phases from the water-induced tetragonal-to-monoclinic transformation [34].

\section{Synthesis from the liquid phase}

Synthesis based on wet chemical methods is a special synthetic approach that allows the attainment of advanced ceramics with controlled size (ranging from micro- to nanoscale) and shape (e.g., powder, fibers, films or monoliths), and with high chemicophysical reactivity as well as high purity control. This approach can be used to synthesize (1) oxidic and non-oxidic, (2) binary, ternary and multicomponent, (3) pure and doped, (4) stable and metastable ceramic materials. Besides that, the liquid phase synthesis allows the formation of fine powders, thin fibers, films and aerogels.

In most cases, wet synthetic methods involve the precipitation (the product contains two elements) or coprecipitation (the product contains more than two elements) of solid particles from soluble precursors in aqueous solutions caused by $\mathrm{pH}$, temperature and precursor concentration changes or by the addition of external agents (oxidizing, reducing and/or stabilizing agents). To be able to tailor the powder properties for specific applications, a certain understanding of the basic mechanisms of nucleation, growth and agglomeration is essential.

The chemical reactions used to induce coprecipitation can involve numerous types, such as addition, exchange, 
oxidation or hydrolysis reactions. For illustrative purposes, we consider the case of a precipitation reaction for the formation of an electrolyte $\mathrm{A}_{x} \mathrm{~B}_{y}$,

$x \mathrm{~A}^{y+}(\mathrm{aq})+y \mathrm{~B}^{x-}(\mathrm{aq}) \rightleftharpoons \mathrm{A}_{x} \mathrm{~B}_{y}(\mathrm{~s})$

The equilibrium relationship between the product and its reactants is expressed as the solubility product constant, $K_{\text {sp: }}$

$K_{\text {sp }}=\left(a_{\mathrm{A}}\right)^{x}\left(a_{\mathrm{B}}\right)^{y}$

where $\mathrm{a}_{\mathrm{A}}$ and $\mathrm{a}_{\mathrm{B}}$ are the activities of cation $\mathrm{A}$ and anion $\mathrm{B}$ in aqueous solution. Tables of $K_{\mathrm{sp}}$ values are widely available in reference volumes and text books. Alternatively, precipitation can be induced by altering other parameters related to solubility, most notably temperature and concentration.

The key to any precipitation process is the degree of supersaturation, denoted as $S$, given by:

$S=\frac{a_{\mathrm{A}} a_{\mathrm{B}}}{K_{\mathrm{sp}}}$

or alternatively by

$S=\frac{C}{C_{\mathrm{eq}}}$

where $C$ and $C_{\text {eq }}$ are the solute concentrations at saturation and equilibrium, respectively. Thus, the driving force of the precipitation is given by the difference in $C$ and $C_{\text {eq }}$ :

$\Delta C=C-C_{\text {eq }}$

Precipitation reactions involve the simultaneous occurrence of nucleation, coarsening and/or agglomeration processes as described by the LaMer model (Fig. 13). Nucleation begins when the nuclei reach a certain critical size. Therefore, nucleated particles with a radius $(R)$ larger than a critical radius $\left(R^{*}\right)$ will continue to grow, while those with $R<R^{*}$ will dissolve. The critical radius can be defined as follows:

$R^{*}=\frac{\alpha}{\Delta C}$

The term $\alpha$ is given by:

$\alpha=\left(\frac{2 \sigma_{\mathrm{SL}}}{k T \ln S}\right){ } C_{\infty}$

where $\sigma_{\mathrm{SL}}$ is the surface tension at the solid-liquid interface, $v$ the atomic volume of the solute, $k$ the Boltzmann constant, $T$ the temperature and $S$ the supersaturation as defined in Eq. 3.

For stationary conditions, the homogeneous nucleation rate $R_{\mathrm{N}}$ is given by:

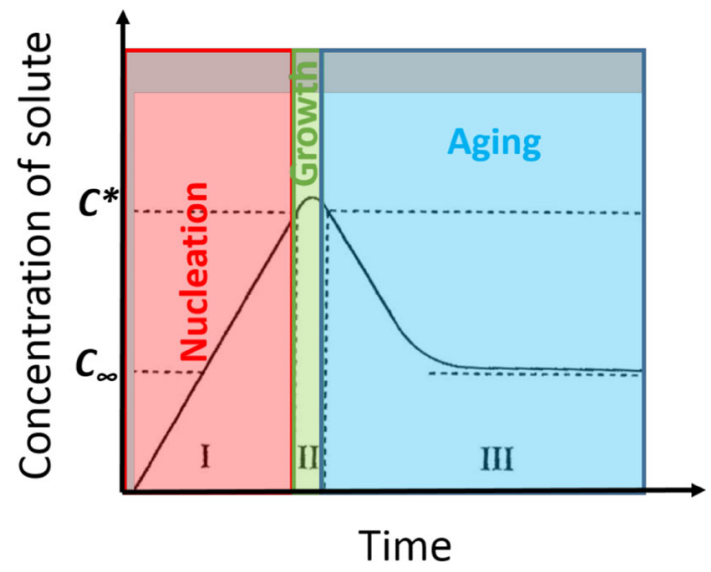

Fig. 13 Schema of LaMer diagram in which the concentration of the monomers is schematically plotted as a time's function. The process of nucleation and growth through the LaMer mechanism is divided into three stages. (I) A rapid increase in the concentration of free monomers in solution, (II) the monomer undergoes "burst nucleation" which significantly reduces the concentration of free monomers in solution. The rate of this nucleation is described as "effectively infinite" and after this point there is almost no nucleation occurring due to the low concentration of monomers after this point; (III) following which nucleation growth occurs under the control of the diffusion of the monomers through the solution

$R_{N}=\left(\frac{\mathrm{d} N}{\mathrm{~d} t}\right) \frac{1}{V}=A \exp \left[\frac{-\left(\Delta G^{*}\right)}{k T}\right]$

where $N$ is the number of nuclei formed per unit time per unit volume, $V, A$ is the pre-exponential factor and $\Delta G^{*}$ is the activation energy for the cluster formation defined as follows:

$\Delta G^{*}=\frac{4 \pi \sigma_{\mathrm{SL}} R^{*^{2}}}{3}=\frac{16 \pi \sigma_{\mathrm{SL}}^{3} v^{2}}{3 k^{2} T^{2} \ln ^{2} S}$

$\Delta G^{*}$ is an exponential function of $S$ and, therefore, remains negligible until a certain critical saturation and $S^{*}$ is reached and the nuclei begin to grow.

The growth process is in general diffusion limited; therefore, concentration gradients and temperature become the main factors determining growth rate as new material is supplied to the particle surface via long-distance mass transfer. The balance of that material as a monomer, crossing the surface of a spherical crystallite, is given by:

$\frac{\mathrm{d} r}{\mathrm{~d} t}=D \Omega\left(\frac{1}{\delta}+\frac{1}{r}\right)\left(C_{\mathrm{b}}-C_{\mathrm{i}}\right)$

where $r$ is the crystal radius, $t$ the time, $D$ the diffusivity of the monomer, $\Omega$ the molar volume and $\delta$ the thickness of the layer over which the concentration changes from $C_{\mathrm{b}}$, the bulk solute concentration, to $C_{\mathrm{i}}$, the solute concentration in the vicinity of the crystal surface. 
Finally, the relationship between the rate of growth, $\mathrm{d} L / \mathrm{d} t$, and the supersaturation, $S$, can be expressed as a power law equation:

$\frac{\mathrm{d} L}{\mathrm{~d} t}=k_{\mathrm{G}} S^{g}$

where $k_{\mathrm{G}}$ is the growth constant and $g$ is the growth order. Besides that, there are some other processes that increase the size of the particles such as Ostwald ripening (also referred to as coarsening) and aggregation/agglomeration. Ostwald ripening is the phenomenon by which smaller particles are essentially consumed by larger particles during the growth process. This behavior can be predicted by the Gibbs-Thomson equation which relates the monomer concentration and the crystal size:

$C_{e}(r) \cong C_{\infty}\left(\frac{1+2 \Omega \gamma}{R T}\right)$

where $\gamma$ is the interfacial tension. This equation establishes that the solubility of particles increases with decreasing particle size.

Agglomeration of small particles precipitated from solutions is practically inevitable in the absence of a stabilizer since the maximization of the surface/volume ratio is thermodynamically favored. However, the particle size of the precipitates can be controlled by three different mechanisms: (a) electrostatic repulsions resulting from the chemisorption of charged species such as, $\mathrm{OH}^{-}$and $\mathrm{H}^{+}$, (b) steric repulsion between particles caused by surfactants, polymers or other organic substances adsorbed on the surface of the particles (generally referred to as capping ligands) and (c) electrosteric which is a combination of the electrostatic and steric repulsion caused by capping charged ligands on the surface of the particles (Fig. 14).

The scheme in Fig. 15 presents a summary of the most important wet chemical methods and the ceramic materials that have been prepared by these techniques.

\section{Sol-gel}

The sol-gel process may be described as "the formation of an oxidic network through the polycondensation reaction of a molecular precursor in a liquid". It has been successfully used for the preparation of oxidic and non-oxidic materials (e.g., ceramics, glasses, films and fibers) throughout the hydrolytic and non-hydrolytic processes (Fig. 16).

Sol-gel procedures have been employed in the search of new low-temperature synthetic routes to produce solidstate materials from chemically homogeneous precursors. By trapping the "randomness of the solution state" and thereby ensuring atomic level mixing of reagents, one should be able to produce complex inorganic materials (such as multinary oxides) at lower processing temperatures and shorter synthesis times. Furthermore, sol-gel chemistry should enable control over particle morphology and size. However, producing a homogeneous precursor at room temperature does not ensure homogeneity throughout a reaction and many sol-gel routes have therefore been designed to control phase segregation during synthesis [35].

\section{Hydrolytic Sol-gel synthesis}

In a hydrolytic sol-gel process, the water, which can be used as a solvent or generated during the reaction, is the oxygen donor. In general, the sol-gel process consists of the following steps (Fig. 17): (1) preparation of a homogeneous solution either by dissolution of metal organic precursors in an organic solvent or by dissolution of inorganic salts in water; (2) conversion of the homogeneous solution into a sol by treatment with a suitable reagent (e.g., water with or without any acid/base); hydrolysis and polycondensation reactions lead to the formation of a colloidal solution, i.e., sol, comprising metal hydroxide

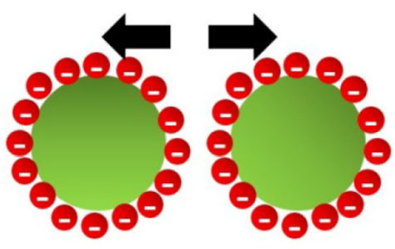

ELECTROSTATIC

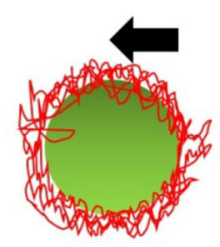

STERIC

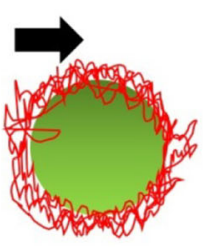

the particle stabilization; (2) steric stabilization is achieved by attaching (grafting or chemisorption) macromolecules to the surfaces of the particles; and (3) in the electrosteric stabilization the polymer attached to charged particle forms a polymer layer (steric restriction) and in addition an electric potential (electrostatic repulsion) to prevent agglomeration 


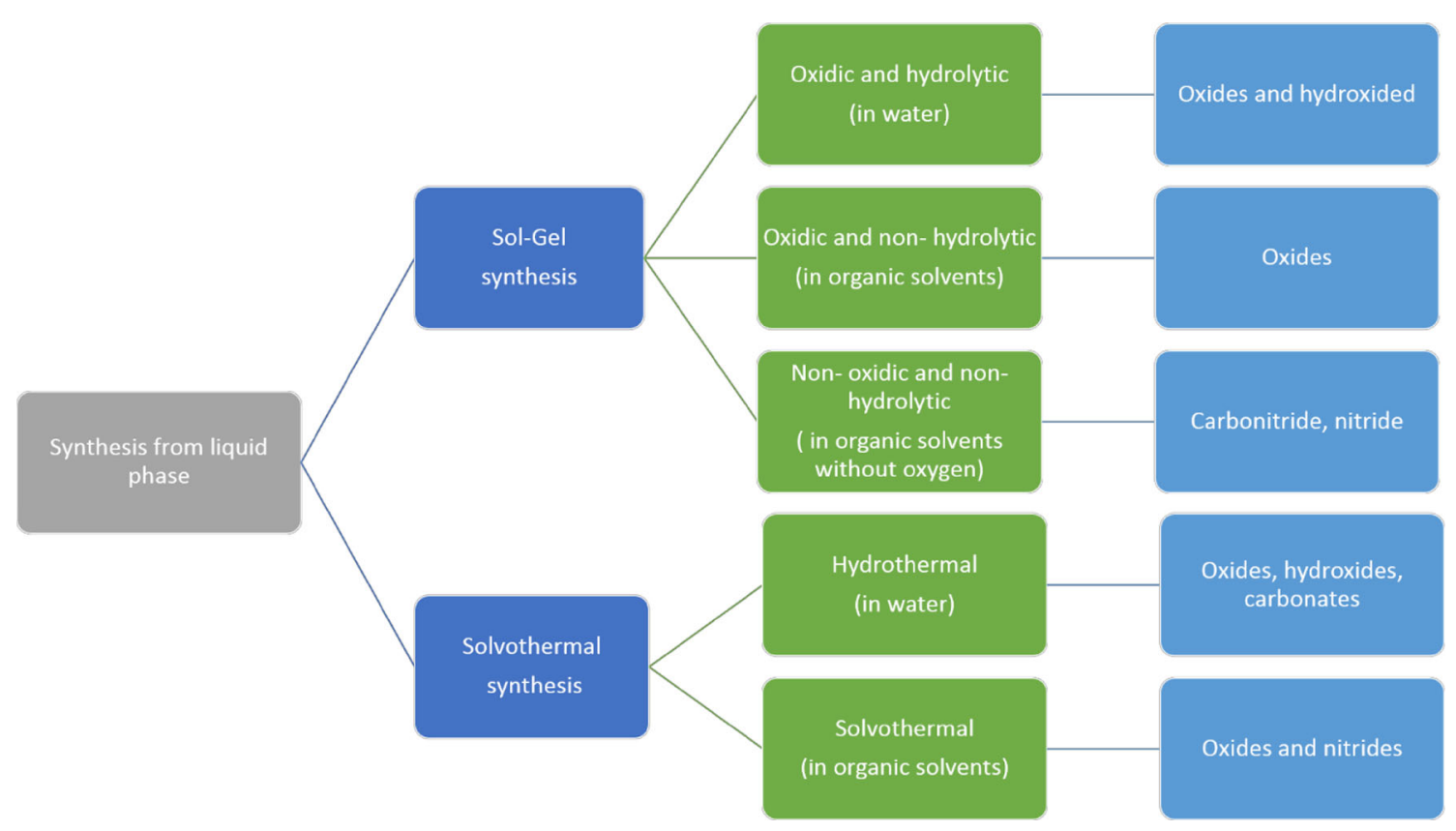

Fig. 15 Methods to synthesize ceramic materials from liquid phases

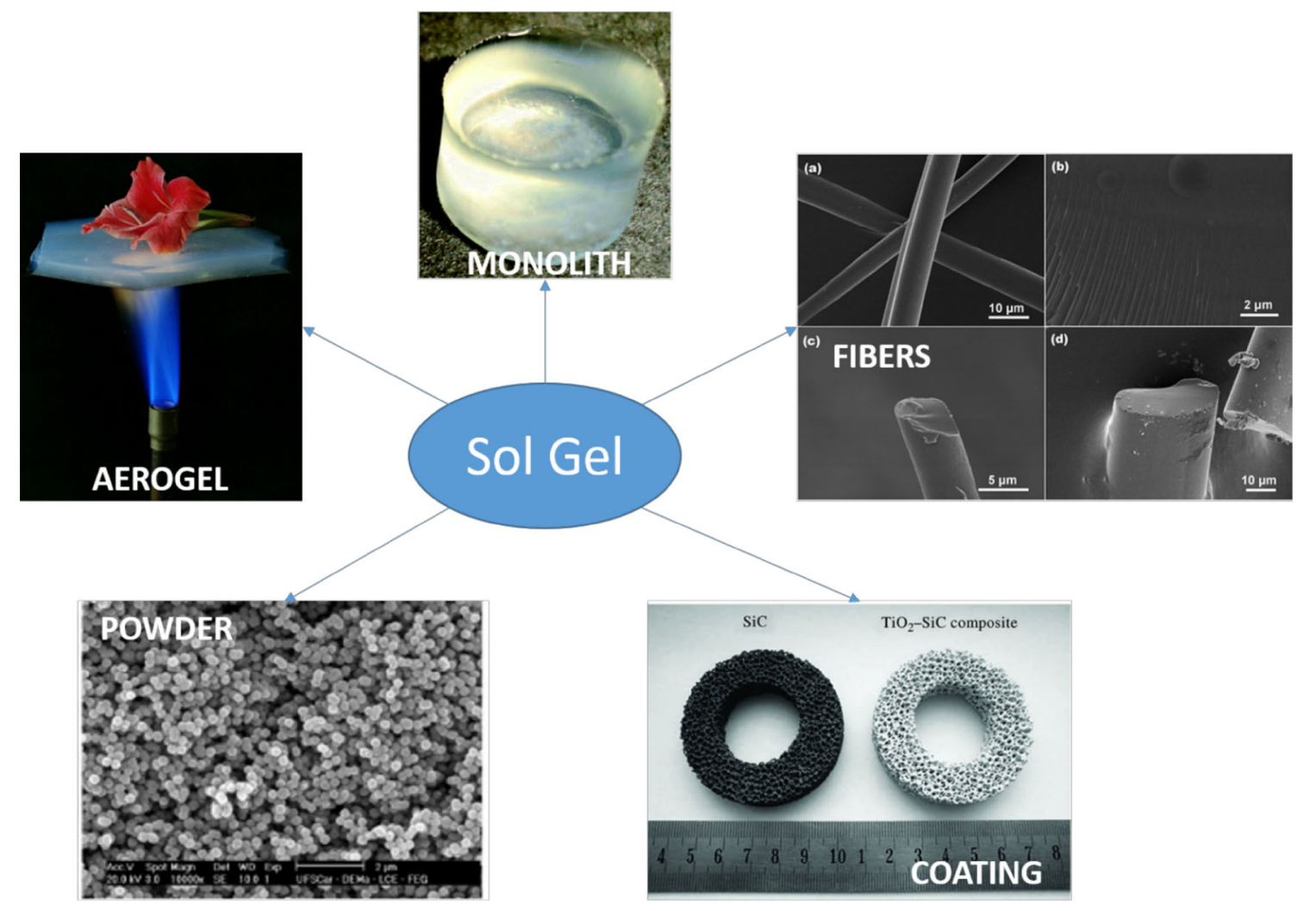

Fig. 16 Overview of the oxidic and non-oxidic materials that can be prepared by sol-gel. ( $\mathrm{SiO}_{2}$ xerogel monolith [55]; $\mathrm{SiOC} / \mathrm{HfO}_{2}$ fibers-reprinted with permission from Ref. [56]-Copyright (c)
2015, Royal Society of Chemistry; $\mathrm{SiO}_{2}$ powder [57]; and $\mathrm{SiC}^{-\mathrm{TiO}_{2}}$ coatings-reprinted with permission from Ref. [58] Copyright (C) 2013 Elsevier B.V) 


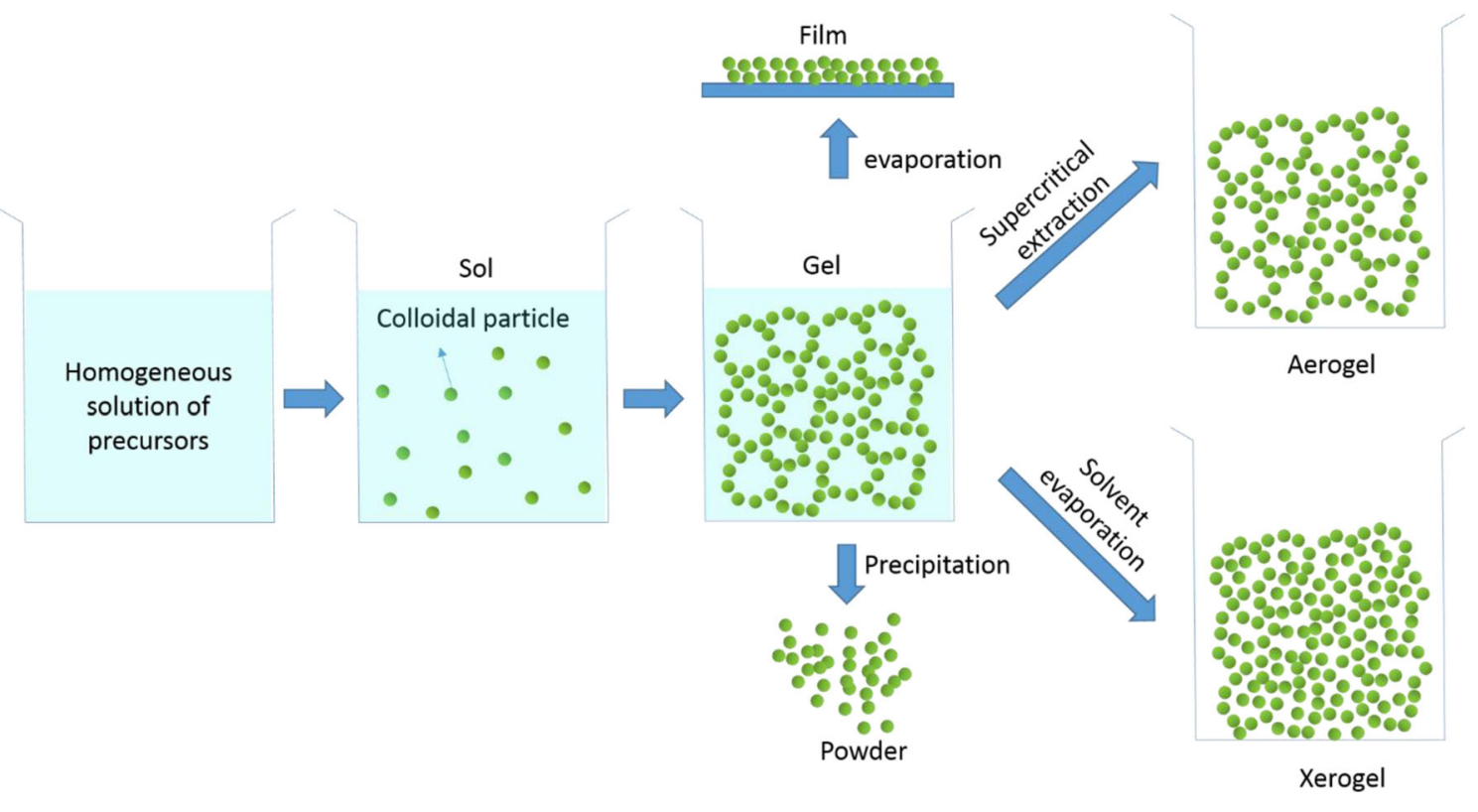

Fig. 17 Scheme of the sol-gel synthesis

particles whose size does not exceed several dozen $\mathrm{nm}$ (colloidal particles); (3) increasing the concentration of the dispersed phase or modifying the external conditions $(\mathrm{pH}$, solvent, precursor) leads to the intense formation of contacts between particles and the formation of a gel, in which the solvent molecules are embedded in a flexible, but fairly stable, three-dimensional network formed by particles of metal hydroxides; (4) drying; and (5) sintering.

The precursors can be either aqueous solutions of inorganic metal salts or metal organic compounds (alkoxides, acetates or acetylacetonates). Among them, the most popular are metal alkoxides due to the following advantages: (1) they are soluble in polar solvents providing high homogeneity and (2) they can easily be converted to the corresponding oxide through the following reactions:

Hydrolysis: The alkoxide groups (-OR) are replaced during the nucleophilic attack of the oxygen atom of the water releasing alcohol and forming the corresponding metal hydroxide. During hydrolysis the solved precursors turn into a solid sol, a dispersion of colloidal particles in a liquid:

$\equiv \mathrm{M}-\mathrm{OR}+\mathrm{H}_{2} \mathrm{O} \rightleftarrows \equiv \mathrm{M}-\mathrm{OH}+\mathrm{ROH}$

Polycondensation: Condensation of the sol results in a gel, an interconnected, rigid and porous inorganic network enclosing a continuous liquid phase. Condensation reactions between the hydroxylated metal species lead to M$\mathrm{O}-\mathrm{M}$ bonds releasing water (oxolation),

$\equiv \mathrm{M}-\mathrm{OH}+\mathrm{HO}-\mathrm{M} \equiv \rightleftarrows \equiv \mathrm{M}-\mathrm{O}-\mathrm{M} \equiv+\mathrm{H}_{2} \mathrm{O}$
In the hydrolytic sol-gel approach, the following aspects have to be considered: (1) the chemical reactivity of the precursor (electronegativity of the metal atom, its ability to increase the coordination number, the steric hindrance of the organic group and its molecular structure), (2) the amount of added water and how the water is added during the hydrolysis step and (3) the polarity, dipole moment and acidity of the solvent used in the solgel process.

Finally, a crucial role in the sol-gel process concerns the removal of the solvent from the gel (drying step). Drying by evaporation under normal conditions gives rise to capillary pressure that causes shrinkage of the gel network due to the liquid located within the pores. The resulting dried gel denoted as "xerogel", a word issued from the Greek word "xeros" and which means dry, is often reduced in volume by a factor of 5-10 compared to the original wet gel. However, when the gel is dried by a supercritical drying process, aerogels are produced. The drying step is performed inside an autoclave which allows overpassing the critical point $\left(P_{\mathrm{C}}, T_{\mathrm{C}}\right)$ of the solvent. Under supercritical conditions, there is no interface between liquid and vapor, which avoids the formation of capillary pressure and results in relatively little shrinkage. Xerogels and aerogels are useful in the preparation of dense ceramics, but they are also interesting themselves, because their high porosity and surface area make them useful materials as catalytic substrates, filters and others [36]. 


\section{Non-hydrolytic sol-gel synthesis}

In the past 20 years, several non-hydrolytic routes to synthesize metal oxides and mixed metal oxides have been developed, involving reactions of suitable precursors (metal chlorides, alkoxides, acetylacetonates, etc.) with oxygen donors (metal alkoxides, ethers, alcohols, acetates, aldehydes, ketones, etc.). The main problem of the aqueous sol-gel approach is to control the hydrolysis and condensation rates. For most transition metal precursors, either organic or inorganic, these reactions are too fast, giving rise to reducing the control of the morphology and the crystal structure of the resulting solid product. These problems increase when two or more metal alkoxides are involved in the sol-gel process to yield a complex multimetal oxide. Due to the different reactivity of the individual precursors, the control of composition and homogeneity of the final complex oxide is a big challenge.

Non-hydrolytic (or non-aqueous) sol-gel processes in organic solvents are able to overcome some of the major limitations of aqueous systems and thus represent a powerful and versatile alternative [30, 37, 38, 40, 41]. Sol-gel syntheses are considered as non-hydrolytic when the oxygen donor is not water, and when water is not generated in situ. The advantages are a direct consequence of the manifold role of the organic components in the reaction system (e.g., solvent, organic ligand of the precursor molecule, surfactants, or in situ formed organic condensation products). Non-aqueous synthesis routes allow the synthesis of oxidic and non-oxidic nanoparticles with uniform, yet complex crystal morphologies, crystallite sizes in the range of just a few nanometers and good dispersibility in organic solvents.

In the synthesis of oxidic compounds, the oxygen is provided either by the solvent (ether, alcohols, ketones or aldehydes) or by the organic constituent of the precursor (alkoxides or acetylacetonates). Furthermore, the organic solvent strongly determines the particle size and shape as well as the surface properties due to their distinct coordination properties.

The most frequently found condensation steps in the formation of a metal-oxygen-metal bond are shown in the following equations. Equation 15 displays the condensation between metal halides and metal alkoxides (formed upon the reaction of metal halides with alcohols) under release of an alkyl halide:

$\equiv \mathrm{M}-\mathrm{X}+\mathrm{R}-\mathrm{O}-\mathrm{M} \equiv \rightleftarrows \equiv \mathrm{M}-\mathrm{O}-\mathrm{M} \equiv+\mathrm{R}-\mathrm{X}$

Ether elimination (Eq. 16) leads to the formation of an $\mathrm{M}-\mathrm{O}-\mathrm{M}$ bond upon condensation of two metal alkoxides under elimination of an organic ether:

$$
\begin{aligned}
\equiv \mathrm{M}-\mathrm{OR}+\mathrm{RO}-\mathrm{M} & \equiv \rightleftarrows \equiv \mathrm{M}-\mathrm{O}-\mathrm{M} \\
& \equiv+\mathrm{R}-\mathrm{O}-\mathrm{R}
\end{aligned}
$$

The ester elimination process involves the reaction between metal carboxylates and metal alkoxides (Eq. 17),

$$
\begin{aligned}
& \equiv \mathrm{M}-\mathrm{O}-\mathrm{COR}+\mathrm{R}-\mathrm{O}-\mathrm{M} \equiv \rightleftarrows \equiv \mathrm{M}-\mathrm{O}-\mathrm{M} \\
& \equiv+\mathrm{RO}-\mathrm{COR}
\end{aligned}
$$

The sol-gel process can be also performed to synthesize non-oxidic ceramics (Fig. 18). For example, silicon carbonitride membranes with enhanced stability for hightemperature applications have been produced using the carbodiimide route (Fig. 19). In this approach, the reaction of trichlorosilane with bis(trimethylsilyl) carbodiimide yields a poly(silyl)carbodiimide. The mechanism of reaction involves the substitution of the trichlorosilane followed by the polycondensation of the polymeric chains. Finally, the gel is pyrolyzed at $1000{ }^{\circ} \mathrm{C}$ in Ar to attain an amorphous $\mathrm{Si}_{x} \mathrm{C}_{z} \mathrm{~N}_{y}$ material [37]. The carbodiimide route has been also successfully developed for the synthesis of GaN by the reaction of Ga-carbodiimide with $\mathrm{NH}_{3}[38]$ and semiconductors such as CdSe and CdTe [39].

\section{Solvothermal synthesis}

Solvothermal research was initialized in the nineteenth century by geologist and was aimed at laboratory simulations of natural hydrothermal phenomena. In the twentieth century, hydrothermal synthesis was clearly identified as an important technology for material synthesis. Solvothermal synthesis is a process that utilizes single or heterogeneous phase reactions in the presence of a solvent (whether aqueous or non-aqueous) above room temperature and at pressures exceeding $1 \mathrm{~atm}$ in a closed system. The method facilitates the synthesis of complex ceramics with the desired physicochemical properties under temperatures ranging between 100 and $400{ }^{\circ} \mathrm{C}$ without any calcination step. Three different synthetic routes can be distinguished in solvothermal processes: (1) precipitation of the solid phase when the reactants are soluble in the solvent; (2) decomposition of the precursor not soluble in the solvent; and (3) crystallization of amorphous starting materials (Figs 20, 21, 22).

The solvothermal approach offers several advantages over other conventional and non-conventional ceramic synthesis methods. Due to the fact that it is a wet synthesis procedure, processes like diffusion, adsorption, dispersion, reaction rate and crystallization are favored, compared to solid-state processes. From the standpoint of ceramic powder production, there are some processing steps which 
Fig. 18 Non-aqueous sol-gel process developed for the synthesis of amorphous $\mathrm{SiCN}$ gels. The gel is produced by the reaction of

methyltrichlorosilane with bis(trimethylsilyl)carbodiimide (reprinted with permission from Ref. [46]-Copyright (C) 2010 WILEY-VCH Verlag GmbH \& Co. KGaA, Weinheim)

\section{Non - oxidic sol gel process}
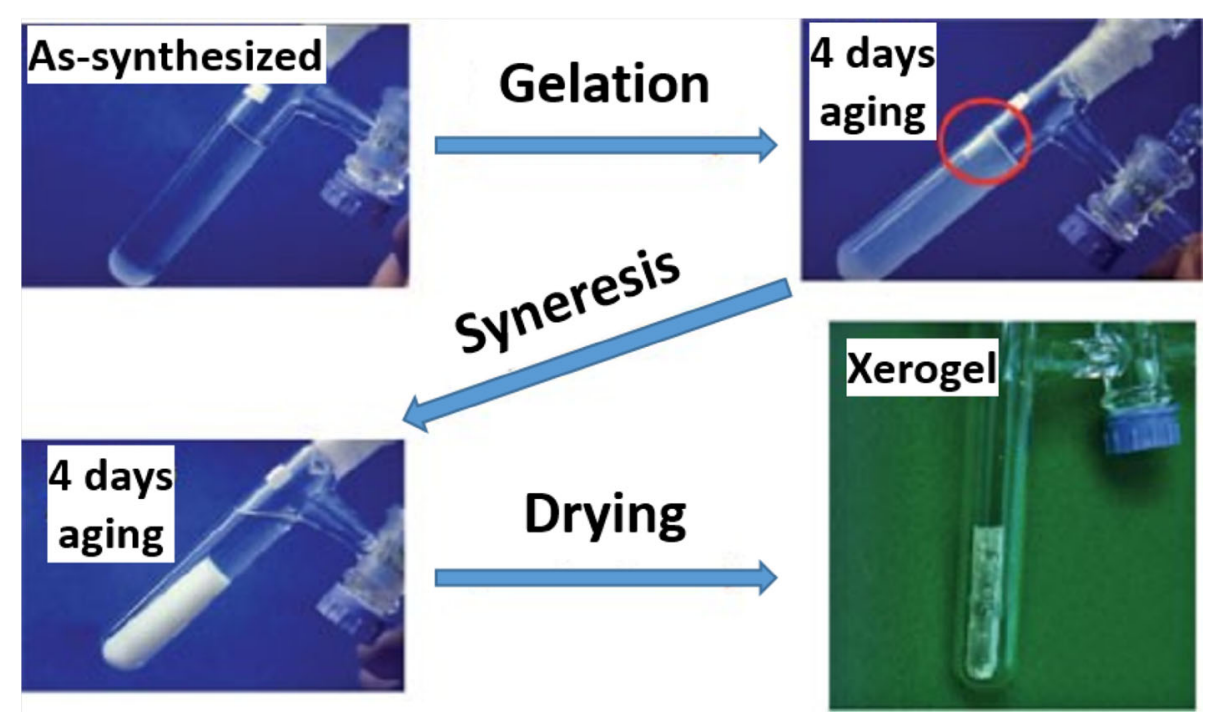

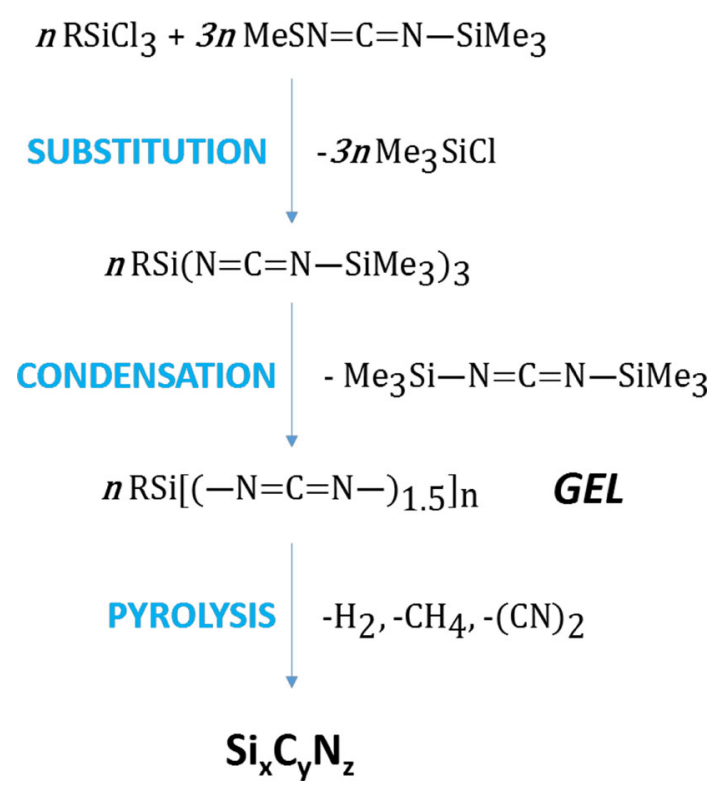

Fig. 19 Scheme of the non-oxide sol-gel process for the synthesis of polysilylcarbodiimides (based on Ref. [37]-Copyright (C) 1998 American Chemical Society)

require high energy consumption like mixing, milling and calcination that are either not necessary or minimized in the solvothermal process. In addition, this approach has the ability to precipitate already crystallized powders directly from the solution. It allows a better control of the rate and uniformity of the nucleation, growth and aging steps which results in an improved control of size and morphology of the crystallites and significantly reduced aggregation levels [40].
Solvothermal synthesis is governed by two parameters: thermodynamic parameters and kinetic parameters.

The thermodynamic parameters involved in a solvothermal process are temperature and pressure. The solvents have different properties at above their boiling point $\left(T_{\mathrm{b}}\right)$, especially at their critical point $\left(T_{\mathrm{c}}\right)$. In terms of temperature, we can distinguish three different regions: superheated conditions $\left(T_{\mathrm{b}}-150^{\circ} \mathrm{C}\right)$, hydro(solvo)themal conditions $\left(150-T_{\mathrm{c}}\right)$ and supercritical conditions $\left(T>T_{\mathrm{c}}\right.$ ). The hydrothermal (solvothermal) reactions are mainly performed under mild temperature conditions $\left(T<400{ }^{\circ} \mathrm{C}\right)$. To explain how the physicochemical properties of the solvents can change by increasing the temperature and pressure, we will take water as an example.

Figure 23 shows the phase diagram of water, in which the critical point marks the end of liquid-vapor coexistence curve at the critical temperature, $T_{\mathrm{c}}$, and pressure, $P_{\mathrm{c}}$, for a pure homogeneous substance. As the temperature increases, the liquid becomes less dense due to thermal expansion and at the same time the gas becomes denser. At the critical point, the densities of both phases become the same. The compound is neither liquid nor gas any longer above the critical point, and it becomes a so-called supercritical fluid (SCF). Subsequently, the phases of liquid and gas are not distinguishable and the physical properties of SCF will be between that of gas and liquid. The dielectric constant (defined as the ability of a solvent to insulate charges) decreases with the temperature and increases with the pressure (Fig. 24a). Since the temperature dependence of the properties is more pronounced than that of the pressure, we can consider that under hydrothermal conditions the dielectric constant is lower than under ambient conditions. 
Fig. $20 \mathrm{ZnO}$ monocrystal [59] (left reprinted by permission of IOP) and $\mathrm{TiO}_{2}$ nanocrystal [1] (right reproduced by permission of The Royal Society of Chemistry)
FROM LARGE SYNGLE CRYSTALS TO NANOPOWDERS

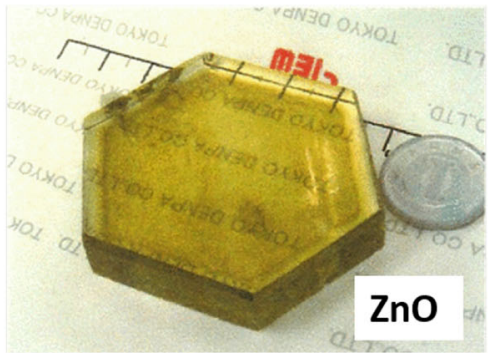

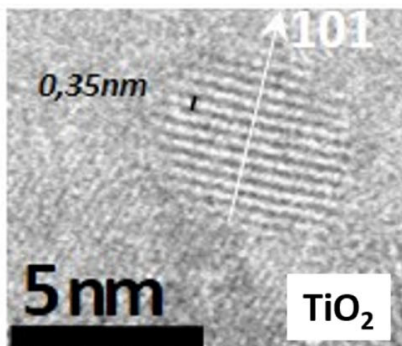
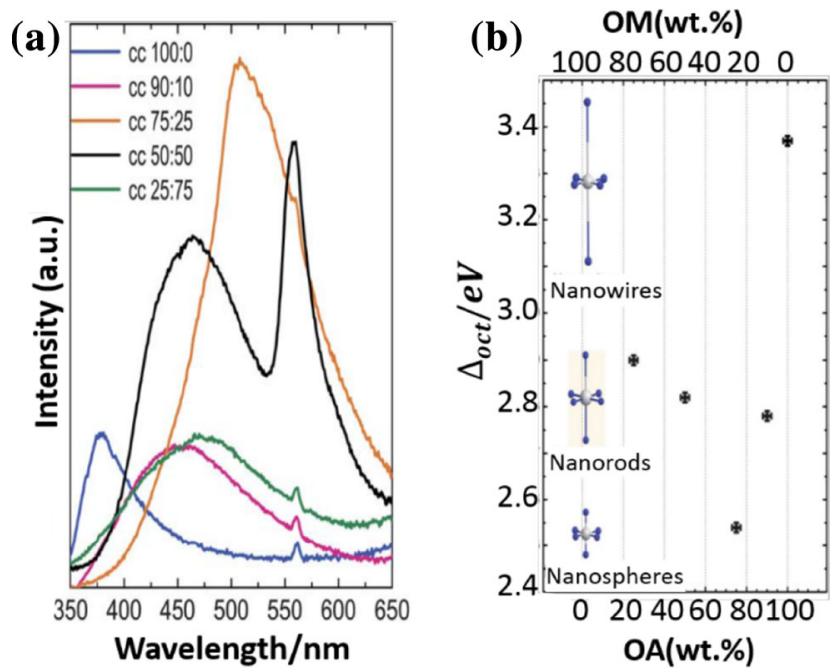

Fig. 21 a Photoluminescence spectra of the coordination complexes, which were obtained by mixing different polymer ligand ratios and b representative energies of $\Delta_{\text {oct }}$ for the coordination complexes obtained using different OA:OM ratios [1] (reproduced by permission of the Royal Society of Chemistry)

This behavior also results in a change in density, as shown in Fig. 24b. Moreover, the ion product increases sharply with pressure and temperature. At high $P-T$ conditions (150-200 kbar and $1000{ }^{\circ} \mathrm{C}$ ), water is completely dissociated into $\mathrm{H}_{3} \mathrm{O}^{+}$and $\mathrm{OH}^{-}$, behaving like a molten salt. Diffusivity and viscosity symbolize the transport properties that influence the rates of mass transfer. Under hydrothermal conditions the diffusivity is at least one order of magnitude higher, whereas viscosity is lower compared with a liquid solvent. This means that the diffusivity of species under hydrothermal conditions will occur faster than that obtained in a liquid solvent. In consequence, solids can dissolve and solved ions migrate more rapidly. The higher densities of liquids relative to gases, and their ability to transport and solubilize a wide range of chemical species, allow for high dissolution rates at low temperatures.

The kinetic parameters are referred mainly to the reaction time and the nature of the precursors and the solvent. If the synthesis is performed in water, the $\mathrm{pH}$ and the ionic strength of the system have to be considered. The chemical composition of the reagents has to be adjusted to that of the target material. In addition, the concentration of the precursors and complexing agents seems to play a role in controlling the shape of the resulting nanocrystals. Various solvents showing distinct different chemical properties are used for solvothermal syntheses and include (1) polar protic solvents such as $\mathrm{H}_{2} \mathrm{O}, \mathrm{NH}_{3}, \mathrm{HF}, \mathrm{HCl}$ and $\mathrm{HBr}$; (2) polar non-protic solvents like tetrahydrofuran and (3) nonpolar solvents such as hexane, benzene, xylene and $\mathrm{CO}_{2}$.

Table 3 gives some examples for solvents used in solvothermal techniques, their critical temperature and pressure points, as well as the obtained products.

The physicochemical properties of the selected solvent play also an important role for orienting the polymorph of the final material. For example, the solvothermal synthesis of $\mathrm{MnS}$ can lead to metastable ( $\beta$ and $\gamma$ ) or stable $(\alpha)$ structural forms depending on the nature of the solvent.
Table 3 Solvothermal solvents, critical temperature $\left(T_{\mathrm{c}}\right)$ and pressure $\left(P_{\mathrm{c}}\right)$ points and materials that can be synthesized

\begin{tabular}{llll}
\hline Solvent & $T_{\mathrm{c}}\left({ }^{\circ} \mathrm{C}\right)$ & $P_{\mathrm{c}}\left({ }^{\circ} \mathrm{C}\right)$ & Materials that can be synthesized \\
\hline $\mathrm{H}_{2} \mathrm{O}$ & 374.1 & 221.2 & Oxide, carbonate, silicate \\
Ammonia & 132.3 & 111 & Amide, imide, nitride \\
Ethanol & 243 & 63.8 & Oxide, hydrolysis sensitive compounds \\
Methanol & 240 & 81 & Oxide, hydrolysis sensitive compounds \\
$\mathrm{CO}_{2}$ & 31.1 & $73.8-76.2$ & Oxide, sulfide, selenide \\
\hline
\end{tabular}


Fig. 22 An example of $\mathrm{TiO}_{2}$ nanoparticles solvothermally synthesized in hexane [1] (reproduced by permission of the Royal Society of Chemistry)
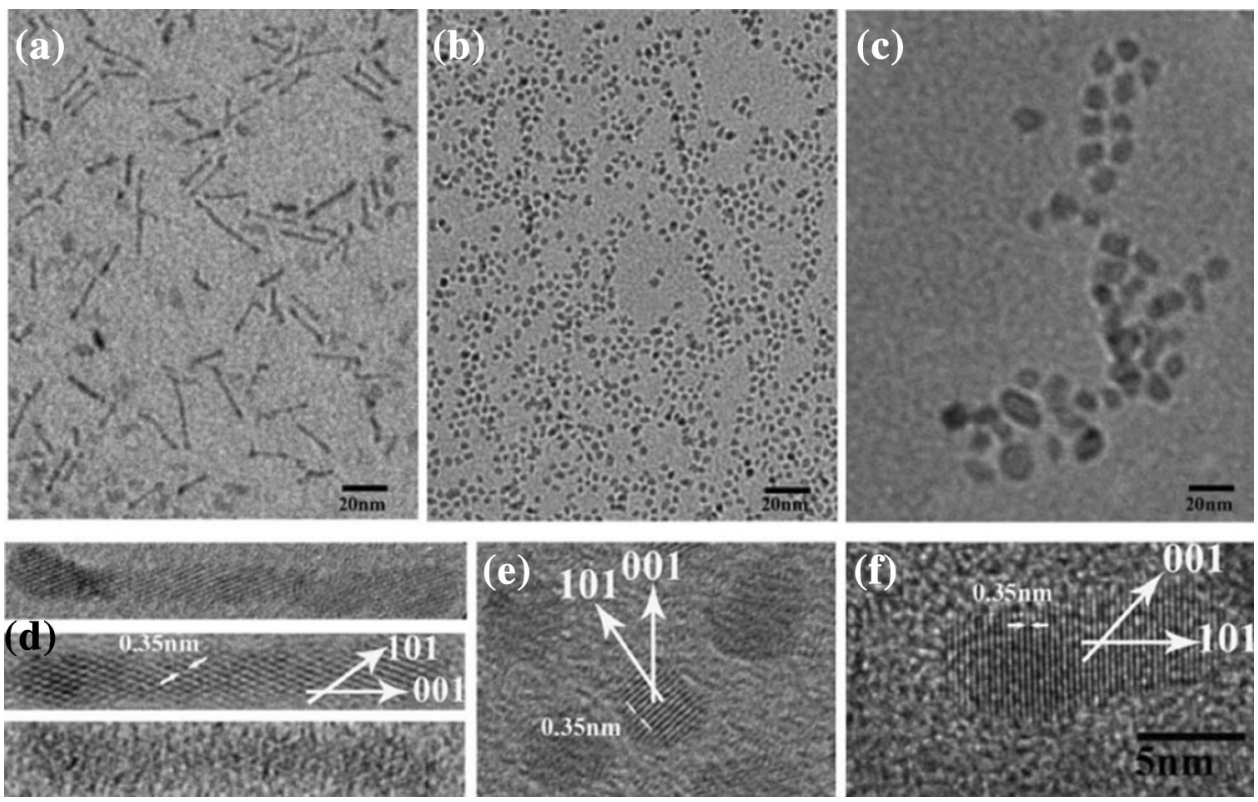

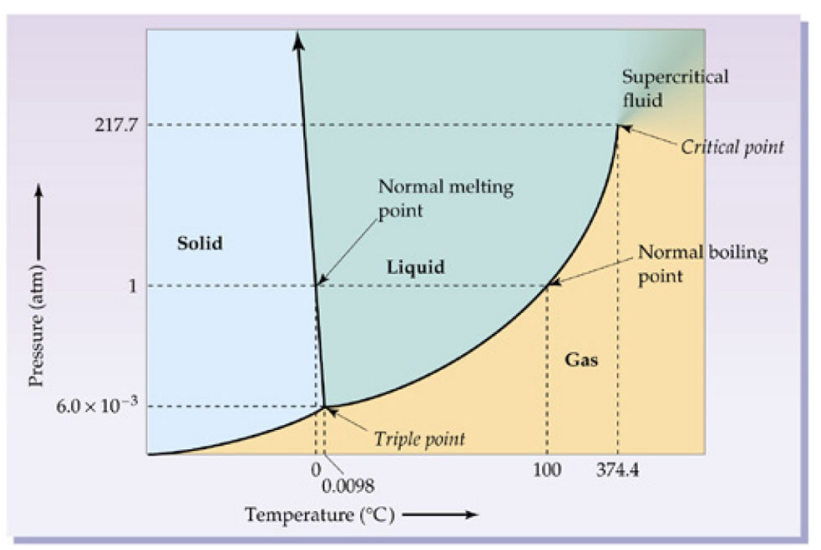

Fig. 23 Phase diagram of water

Using $\mathrm{MnCl}_{2} \times 4 \mathrm{H}_{2} \mathrm{O}$ and $\mathrm{SC}\left(\mathrm{NH}_{2}\right)_{2}$ as reagents and either using water or ethylenediamine as solvents, the $\alpha$ polymorph of $\mathrm{MnS}$ is formed. However, with benzene as the solvent, the $\gamma$-phase is obtained, whereas with tetrahydrofuran the $\beta$-phase is obtained. The stabilization of different polymorphs can be attributed to the ability of the solvents to form stable and distinct complexes with the solved metal ions involved in the reaction process. With Mn ions, water and ethylenediamine form stable complexes such as, $\left[\mathrm{Mn}\left(\mathrm{H}_{2} \mathrm{O}\right)_{6}\right]^{2+}$ and $\left[\mathrm{Mn}(\mathrm{en})_{3}\right]^{2+}$ which lead to the formation of the thermodynamically stable $\alpha$-phase. However, for the metastable phases, a non-polar solvent like benzene is more appropriated to stabilize the $\gamma$-phase, whereas the polar solvent tetrahydrofuran is more suitable to obtain the metastable $\beta$-phase.
The apparatuses available nowadays to perform solvothermal synthesis are batch autoclaves and continuous flow autoclaves (Fig. 25). Subcritical solvothermal synthesis is commonly performed using Teflon ${ }^{\mathrm{TM}}$-lined, stainless steel autoclaves, as shown in Fig. 25 on the left side. The use of an autoclave is necessitated by the pressures developed in solvothermal reactions, and the inert liner is used to protect the stainless steel outer shell from corrosive reagents like acids and bases typically used in solvothermal reactions. Such autoclaves can be used up to $260{ }^{\circ} \mathrm{C}$ (melting point of Teflon ${ }_{\mathrm{TM}}$ ), and depending on the specification of the steel walls, pressures of around 150 bar can be maintained. In the continuous solvothermal synthesis, the aim is to increase the temperature of the compressed cold precursors up to near critical or supercritical conditions very rapidly through mixing them with a sufficient hot water stream. A feature of this approach is that, as a result of the faster and more homogeneous temperature change, particle formation is faster and generally leads to a more uniform particle size and smaller particles [41].

The type of materials synthesized hydrothermally are, in most cases, oxides, phosphates and silicates. The oxides can be simple oxides such as $\mathrm{ZrO}_{2}, \mathrm{TiO}_{2}, \mathrm{SiO}_{2}, \mathrm{ZnO}$, $\mathrm{Fe}_{2} \mathrm{O}_{3}$ and $\mathrm{Al}_{2} \mathrm{O}_{3}$, or complex oxides such as $\mathrm{BaTiO}_{3}$, $\mathrm{LiNbO}_{3}$ and $\mathrm{BaFe}_{2} \mathrm{O}_{3}$ [42]. The hydrothermal method can be used to prepare metastable compounds, such as tungstates (e.g., $\mathrm{ZnWO}_{4}, \mathrm{Bi}_{2} \mathrm{WO}_{6}$ ), vanadates (e.g., $\mathrm{YVO}_{4}$ ) and molybdates (e.g., $\mathrm{CdMoO}_{4}, \mathrm{Bi}_{2} \mathrm{MO}_{6}, \mathrm{BaMo}_{2} \mathrm{O}_{7}$ ) [43] and zeolites, for example $\mathrm{Na}_{n} \mathrm{Al}_{n} \mathrm{Si}_{96-n} \mathrm{O}_{192} \times 16 \mathrm{H}_{2} \mathrm{O}, n<27$ (ZMS-5), and $\mathrm{Na}_{8} \mathrm{Al}_{8} \mathrm{Si}_{140} \mathrm{O}_{96} \times 24 \mathrm{H}_{2} \mathrm{O}$ (modernite) [44], 
Fig. 24 Variation of a dielectric constant (reprinted with permission from Ref. [61]-Copyright (C) 1987 American Chemical Society) and $\mathbf{b}$ density of water with temperature and pressure (reprinted with permission from Ref. [62]) (a)

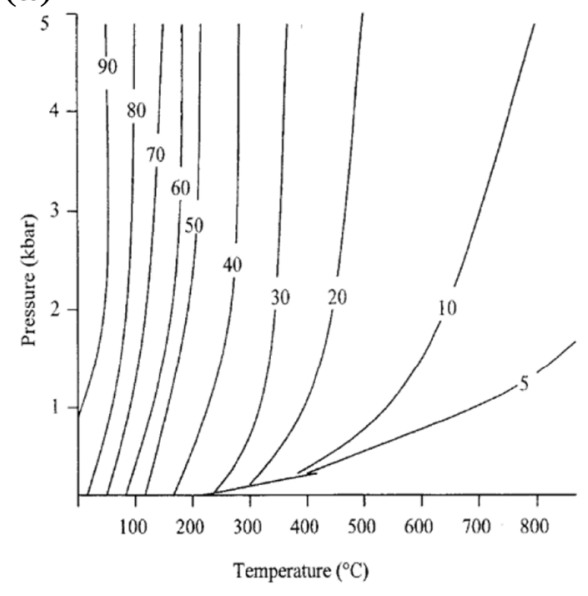

(b)
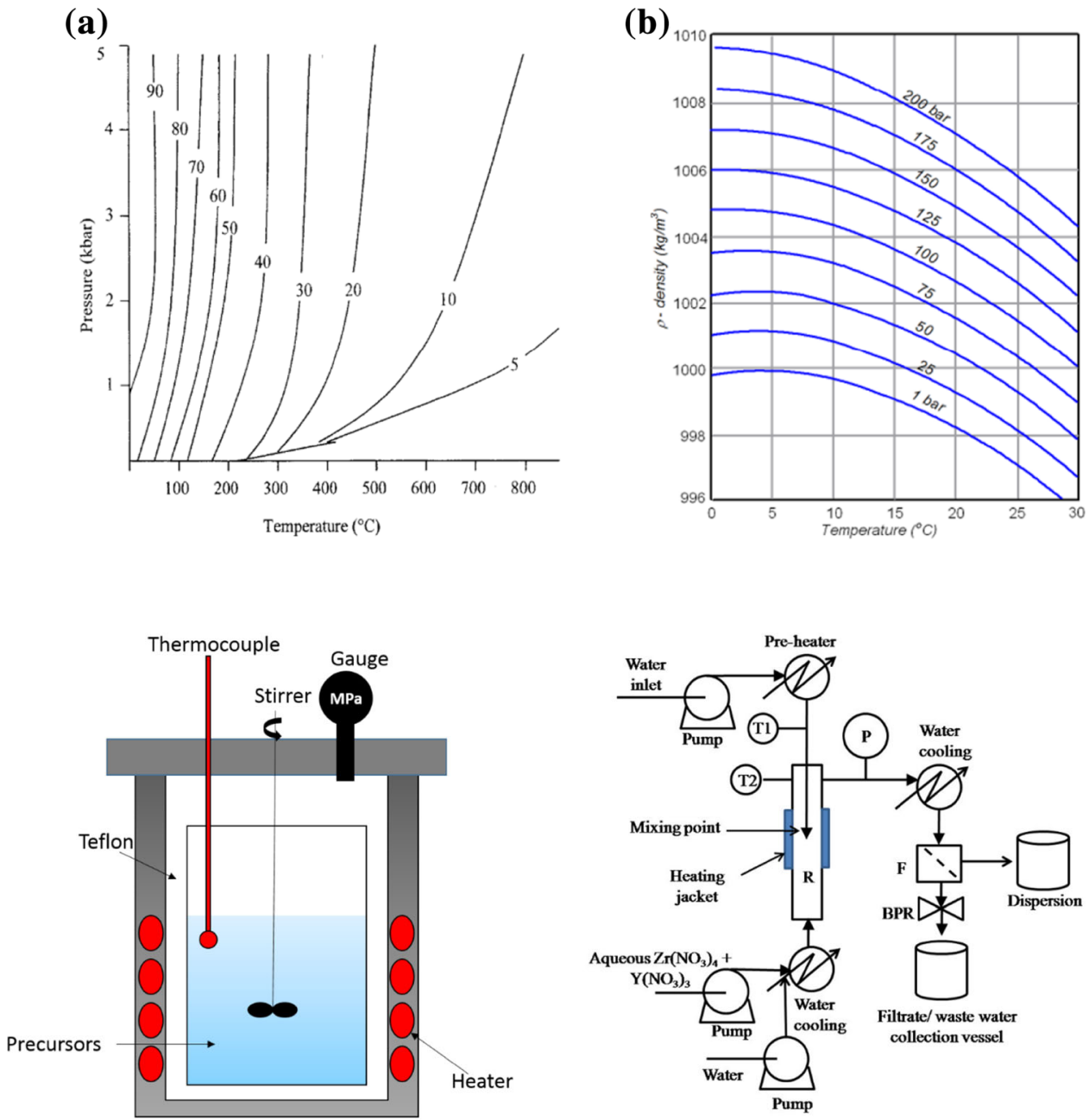

Batch autoclave

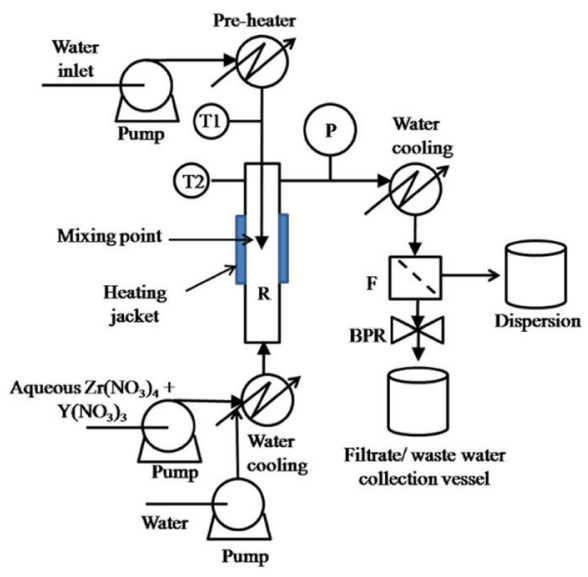

Continuous flow autoclave many of which may not be obtained when using classical synthesis reactions. The method is also suitable to prepare high purity monocrystals in large scale for industrial purposes, such as, quartz, $\mathrm{ZnO}$, sapphire and ruby. Moreover, non-aqueous solvothermal synthesis can be also used to synthesize non-oxidic materials such as nitrides, imides, sulfides and telurides by choosing a suitable solvent (Table 3). For example, the ammonothermal method has considerably increased the research interest over the past 20 years, since it is one of the few techniques leading to group III bulk nitrides. In comparison to other techniques, the ammonothermal method allows crystal growth on native substrates and growth of the initial native substrate itself in high quality. Increasing commercial efforts are directed to the ammonothermal growth of $\mathrm{GaN}$ and $\mathrm{AlN}$ on native substrates. GaN and AlN are semiconductors with wide band gaps used as base for optoelectronic and electronic devices (e.g., light-emitting diodes (LEDs), high electron mobility transistors, lasers with high optical storage capacity) [45].

\section{Summary and outlook}

Since the discovery by early man that rocks could be modified to make tools, the world has demanded materials with increasingly complex functionality. Advanced materials are essential to address challenges in clean energy, national security and human well-being. Subsequently, one of the primary research goals has become the development of new materials to reach advanced functional properties, such as chemical reactivity, thermal stability, catalytic activity or optical, magnetic and electronic properties, to achieve better performances and novel applications. Naturally, this has to led to the improvement of the classical synthetic techniques and the development of new synthetic approaches.

Many inorganic materials, such as metal oxides or carbides, can be prepared fairly simply by mixing powdered reactants and heating them to give the desired product. While reaction conditions are relatively easy to achieve (furnace technology being well 
established), there are some drawbacks, such as the inhomogeneity of the starting materials and the difficulty to control particle size and morphology. Therefore, novel synthetic methods, many of them detailed in this chapter, have been developed in the past decades to prepare advanced ceramics as an alternative to the solid-state synthesis of materials to overcome the aforementioned limitations.

\section{References}

1. Gonzalo-Juan I, McBride JR, Dickerson JH (2011) Ligand-mediated shape control in the solvothermal synthesis of titanium dioxide nanospheres, nanorods and nanowires. Nanoscale 3(9):3799-3804

2. Rao CNR, Gopalakrishnan J (1997) New directions in solid state chemistry, 2nd edn. Cambridge University Press, Cambridge. doi:10.1017/CBO9780511623141

3. Bridgman PW (1952) The resistance of 72 elements, alloys and compounds to $100,000 \mathrm{~kg} / \mathrm{Cm}^{2}$. Proc Am Acad Arts Sci 81(4):165-251

4. Dunstan DJ (1996) High pressure experimental methods. Meas Sci Technol 7(9). doi:10.1088/0957-0233/7/9/017

5. Holzapfel WB, Isaacs NS (eds) (1997) High-pressure techniques in chemistry and physics: a practical approach. Oxford University Press, Oxford

6. Chen J, Wang Y, Duffy TS, Shen G (2005) Advances in highpressure technology for geophysical applications. Elsevier, Amsterdam, p xv

7. Raizer YP, Zel'dovich YB (1967) XI-Shock waves in solids. In: Probstein RF, Hayes WD (eds) Physics of shock waves and hightemperature hydrodynamic phenomena. Academic Press, pp 685-784

8. Zerr A, Miehe G, Serghiou G, Schwarz M, Kroke E, Riedel R, Fuesz H, Kroll P, Boehler R (1999) Synthesis of cubic silicon nitride. Nature 400(6742):340-342

9. Bhat S, Wiehl L, Molina-Luna L, Mugnaioli E, Lauterbach S, Sicolo S, Kroll P, Duerrschnabel M, Nishiyama N, Kolb U, Albe K, Kleebe H-J, Riedel R (2015) High-pressure synthesis of novel boron oxynitride B6N4O3 with sphalerite type structure. Chem Mater 27(17):5907-5914

10. Zerr A, Miehe G, Riedel R (2003) Synthesis of cubic zirconium and hafnium nitride having Th3P4 structure. Nat Mater 2(3):185-189

11. Lei F, Yan B, Chen HH, Zhao JT (2009) Molten salt synthesis, characterization, and luminescence properties of Gd2MO6:Eu3 + $(\mathrm{M}=\mathrm{W}, \mathrm{Mo})$ phosphors. J Am Ceram Soc 92(6):1262-1267

12. Yan B, Lei F (2010) Molten salt synthesis, characterization and luminescence of ZnWO4:Eu3 + nanophosphors. J Alloys Compd 507(2):460-464

13. Riedel R, Mera G, Hauser R, Klonczynski A (2006) Silicon-based polymer-derived ceramics: synthesis properties and applications - a review dedicated to Prof. Dr. Fritz Aldinger on the occasion of his 65th birthday. J Ceram Soc Jpn 114(1330):425-444

14. Greil P (2000) Polymer derived engineering ceramics. Adv Eng Mater 2(6):339-348

15. Soraru GD, Babonneau F, Mackenzie JD (1988) Structural concepts on new amorphous covalent solids. J Non-Cryst Solids 106(1):256-261
16. Monthioux M, Oberlin A, Bouillon E (1990) Relationship between microtexture and electrical properties during heat treatment of SiC fibre precursor. Compos Sci Technol 37(1-3):21-35

17. Babonneau F, Thorne K, Mackenzie JD (1989) Dimethyldiethoxysilane/tetraethoxysilane copolymers: precursors for the silicon-carbon-oxygen system. Chem Mater 1(5):554-558

18. Corriu RJP, Leclercq D, Mutin PH, Vioux A (1997) Preparation and structure of silicon oxycarbide glasses derived from polysiloxane precursors. J Sol-Gel Sci Technol 8(1-3):327-330

19. Pantano C, Singh A, Zhang H (1999) Silicon oxycarbide glasses. J Sol-Gel Sci Technol 14(1):7-25

20. Belot V, Corriu RJP, Leclercq D, Mutin PH, Vioux A (1992) Thermal redistribution reactions in crosslinked polysiloxanes. J Polym Sci, Part A: Polym Chem 30(4):613-623

21. Iwamoto Y, Völger W, Kroke E, Riedel R, Saitou T, Matsunaga K (2001) Crystallization behavior of amorphous silicon carbonitride ceramics derived from organometallic precursors. J Am Ceram Soc 84(10):2170-2178

22. Colombo P, Mera G, Riedel R, Sorarù GD (2010) Polymerderived ceramics: 40 years of research and innovation in advanced ceramics. J Am Ceram Soc 93(7):1805-1837

23. Mera G, Riedel R, Poli F, Müller K (2009) Carbon-rich SiCN ceramics derived from phenyl-containing poly(silylcarbodiimides). J Eur Ceram Soc 29(13):2873-2883

24. Michelle Morcos R, Mera G, Navrotsky A, Varga T, Riedel R, Poli F, Müller K (2008) Enthalpy of formation of carbon-rich polymer-derived amorphous SiCN ceramics. J Am Ceram Soc 91(10):3349-3354

25. Mera G, Tamayo A, Nguyen H, Sen S, Riedel R (2010) Nanodomain structure of carbon-rich silicon carbonitride polymerderived ceramics. J Am Ceram Soc 93(4):1169-1175

26. Gao Y, Mera G, Nguyen H, Morita K, Kleebe H-J, Riedel R (2012) Processing route dramatically influencing the nanostructure of carbon-rich $\mathrm{SiCN}$ and $\mathrm{SiBCN}$ polymer-derived ceramics. Part I: low temperature thermal transformation. J Eur Ceram Soc 32(9): 1857-1866

27. Mera G, Navrotsky A, Sen S, Kleebe H-J, Riedel R (2013) Polymer-derived SiCN and SiOC ceramics-structure and energetics at the nanoscale. J Mater Chem A 1(12):3826-3836

28. Greil P (1995) Active-filler-controlled pyrolysis of preceramic polymers. J Am Ceram Soc 78(4):835-848

29. Seyferth D, Bryson N, Workman DP, Sobon CA (1991) Preceramic polymers as "reagents" in the preparation of ceramics. J Am Ceram Soc 74(10):2687-2689

30. Harshe R, Balan C, Riedel R (2004) Amorphous Si(Al)OC ceramic from polysiloxanes: bulk ceramic processing, crystallization behavior and applications. J Eur Ceram Soc 24(12):3471-3482

31. Ionescu E, Papendorf B, Kleebe H-J, Riedel R (2010) Polymerderived silicon oxycarbide/hafnia ceramic nanocomposites. Part II: stability toward decomposition and microstructure evolution at $\mathrm{T} \gg 1000{ }^{\circ} \mathrm{C}$. J Am Ceram Soc 93(6):1783-1789

32. Ionescu E, Linck C, Fasel C, Müller M, Kleebe HJ, Riedel R (2010) Polymer-derived $\mathrm{SiOC} / \mathrm{ZrO} 2$ ceramic nanocomposites with excellent high-temperature stability. J Am Ceram Soc 93(1):241-250

33. Papendorf B, Ionescu E, Kleebe H-J, Linck C, Guillon O, Nonnenmacher K, Riedel R (2013) High-temperature creep behavior of dense SiOC-based ceramic nanocomposites: microstructural and phase composition effects. J Am Ceram Soc 96(1):272-280

34. Linck C, Ionescu E, Papendorf B, Galuskova D, Galusek D, Sajgalík P, Riedel R (2012) Corrosion behavior of silicon oxycarbide-based ceramic nanocomposites under hydrothermal conditions. Int J Mater Res 103(1):31-39

35. Danks AE, Hall SR, Schnepp Z (2016) The evolution of 'sol-gel' chemistry as a technique for materials synthesis. Mater Horiz 3(2):91-112 
36. Brinker C, Scherer G (1990) Sol-gel science: the physics and chemistry of sol-gel processing. Academic Press, San Diego

37. Riedel R, Kroke E, Greiner A, Gabriel AO, Ruwisch L, Nicolich J, Kroll P (1998) Inorganic solid-state chemistry with main group element carbodiimides. Chem Mater 10(10):2964-2979

38. Rodewald D, Bill J, Beck U, Puchinger M, Wagner T, Greiner A, Aldinger F (1999) GaN derived from carbodiimide-based polymeric precursors. Adv Mater 11(18):1502-1504

39. Gaponik N, Wolf A, Marx R, Lesnyak V, Schilling K, Eychmüller A (2008) Three-dimensional self-assembly of thiol-capped CdTe nanocrystals: gels and aerogels as building blocks for nanotechnology. Adv Mater 20(22):4257-4262

40. Riman RE, Suchanek WL, Lencka MM (2002) Hydrothermal crystallization of ceramics. Annales de Chimie Science des Matériaux 27(6):15-36

41. Adschiri T, Hakuta Y, Sue K, Arai K (2001) Hydrothermal synthesis of metal oxide nanoparticles at supercritical conditions. J Nanopart Res 3(2-3):227-235

42. Wojciech LS, Richard ER (2006) Hydrothemal synthesis of advanced ceamics. Adv Sci Technol 45:184-196

43. Jolivet J-P (2000) Metal oxide chemistry and synthesis. From solution to solid state. Wiley, Chichester

44. Chen H, Wydra J, Zhang X, Lee P-S, Wang Z, Fan W, Tsapatsis M (2011) Hydrothermal synthesis of zeolites with three-dimensionally ordered mesoporous-imprinted structure. J Am Chem Soc 133(32):12390-12393

45. Klimm D (2014) Electronic materials with a wide band gap: recent developments. IUCrJ 1:281-290

46. Riedel R, Gurlo A, Ionescu E (2010) Synthesemethoden für keramische Materialien. Hochtechnologiewerkstoffe. Chem Unserer Zeit 44(3):208-227

47. Gong M, Lu F, Kuang X, Yu X, Wang Q, Li X, Fang L (2015) Molten salt synthesis, polymorphism, and microwave dielectric properties of Ba8NiTa6O24 perovskite. J Am Ceram Soc 98(8):2451-2458

48. Ulker Z, Erkey C (2014) A novel hybrid material: an inorganic silica aerogel core encapsulated with a tunable organic alginate aerogel layer. RSC Adv 4(107):62362-62366

49. Clariant. http://clariant.com. Accessed 1 June 2015

50. Dzivenko DA, Riedel R (2011) High-pressure routes to ceramics. In: Riedel R, Chen I-W (eds) Ceramics science and technology, vol 3. Wiley-VCH Verlag GmbH \& Co. KGaA, Weinheim, pp 501-517
51. Chen J, Yu R, Li L, Sun C, Zhang T, Chen H, Xing X (2008) Structure and shape evolution of $\mathrm{Bi} 1-\mathrm{xLaxFeO} 3$ perovskite microcrystals by molten salt synthesis. Eur J Inorg Chem 23:3655-3660

52. Liu X, Antonietti M, Giordano C (2013) Manipulation of phase and microstructure at nanoscale for $\mathrm{SiC}$ in molten salt synthesis. Chem Mater 25(10):2021-2027

53. Mera G, Gallei M, Bernard S, Ionescu E (2015) Ceramic nanocomposites from Tailor-Made preceramic polymers. Nanomaterials 5(2):468

54. Xu T, Ma Q, Chen Z (2012) Structural evolution of Al-doped SiAlOC polymer in inert atmosphere. Mater Lett 66(1):364-366

55. Mohallem NDS, Batista Silva J, Tacchi Nascimento G, Guimarães V (2012) Study of multifunctional nanocomposites formed by cobalt ferrite dispersed in a silica matrix prepared by sol-gel process. In: Ebrahimi DF (ed) Nanocomposites: new trends and developments. InTech, Hampshire

56. Xu Y, Su D, Feng H, Yan X, Liu N, Sun Y (2015) Continuous sol-gel derived $\mathrm{SiOC} / \mathrm{HfO} 2$ fibers with high strength. RSC Adv 5(44):35026-35032

57. Nassar EJ, Ciuffi KJ, Calefi PS, Rocha LA, De Faria EH, e Silva MLA, Luz PP, Bandeira LC, Cestari A, Fernandes CN (2011) Biomaterials and sol-gel process: a methodology for the preparation of functional materials. In: Pignatello PR (ed) Biomaterials science and engineering. InTech, Hampshire

58. Hao D, Yang Z, Jiang C, Zhang J (2014) Synergistic photocatalytic effect of $\mathrm{TiO} 2$ coatings and p-type semiconductive $\mathrm{SiC}$ foam supports for degradation of organic contaminant. Appl Catal B 144:196-202

59. Katsumi M, Mitsuru S, Ikuo N, Tsuguo F (2005) Growth of 2 inch $\mathrm{ZnO}$ bulk single crystal by the hydrothermal method. Semicond Sci Technol 20(4):S49

60. Gonzalo-Juan I, Ferrari B, Colomer MT, Rodriguez MA, Sanchez-Herencia AJ, Koh PY, Teja AS (2012) Synthesis and dispersion of yttria-stabilized zirconia (YSZ) nanoparticles in supercritical water. Mater Chem Phys 134(1):451-458

61. Laudise RA (1987) Hydrothermal synthesis of crystals. C\&EN Arch 65(39):30-43

62. The engineering toolbox. http://www.engineeringtoolbox.com/. Accessed 1 June 2015 